\title{
A New Type of $\mathrm{Na}^{+}$-Driven ATP Synthase Membrane Rotor with a Two-Carboxylate lon-Coupling Motif
}

\author{
Sarah Schulz ${ }^{1}$, Marina Iglesias-Cans ${ }^{2}$, Alexander Krah ${ }^{3}$, Özkan Yildiz ${ }^{1}$, Vanessa Leone ${ }^{3}$, Doreen Matthies ${ }^{1}$, \\ Gregory M. Cook ${ }^{2}$, José D. Faraldo-Gómez ${ }^{3,4 * 9}$, Thomas Meier ${ }^{1,4 * 9}$
}

1 Department of Structural Biology, Max Planck Institute of Biophysics, Frankfurt am Main, Germany, 2 Department of Microbiology and Immunology, Otago School of Medical Sciences, University of Otago, Dunedin, New Zealand, 3 Theoretical Molecular Biophysics Group, Max Planck Institute of Biophysics, Frankfurt am Main, Germany, 4 Cluster of Excellence "Macromolecular Complexes," Goethe University of Frankfurt, Frankfurt am Main, Germany

\begin{abstract}
The anaerobic bacterium Fusobacterium nucleatum uses glutamate decarboxylation to generate a transmembrane gradient of $\mathrm{Na}^{+}$. Here, we demonstrate that this ion-motive force is directly coupled to ATP synthesis, via an $\mathrm{F}_{1} \mathrm{~F}_{\mathrm{o}}-\mathrm{ATP}_{\text {, synthase with a }}$ novel $\mathrm{Na}^{+}$recognition motif, shared by other human pathogens. Molecular modeling and free-energy simulations of the rotary element of the enzyme, the c-ring, indicate $\mathrm{Na}^{+}$specificity in physiological settings. Consistently, activity measurements showed $\mathrm{Na}^{+}$stimulation of the enzyme, either membrane-embedded or isolated, and ATP synthesis was sensitive to the $\mathrm{Na}^{+}$ionophore monensin. Furthermore, $\mathrm{Na}^{+}$has a protective effect against inhibitors targeting the ionbinding sites, both in the complete ATP synthase and the isolated c-ring. Definitive evidence of $\mathrm{Na}^{+}$coupling is provided by two identical crystal structures of the $c_{11}$ ring, solved by X-ray crystallography at 2.2 and $2.6 \AA$ resolution, at $\mathrm{pH} 5.3$ and 8.7 , respectively. $\mathrm{Na}^{+}$ions occupy all binding sites, each coordinated by four amino acids and a water molecule. Intriguingly, two carboxylates instead of one mediate ion binding. Simulations and experiments demonstrate that this motif implies that a proton is concurrently bound to all sites, although $\mathrm{Na}^{+}$alone drives the rotary mechanism. The structure thus reveals a new mode of ion coupling in ATP synthases and provides a basis for drug-design efforts against this opportunistic pathogen.
\end{abstract}

Citation: Schulz S, Iglesias-Cans M, Krah A, Yildiz Ö, Leone V, et al. (2013) A New Type of Na+-Driven ATP Synthase Membrane Rotor with a Two-Carboxylate lonCoupling Motif. PLoS Biol 11(6): e1001596. doi:10.1371/journal.pbio.1001596

Academic Editor: Raimund Dutzler, University of Zurich, Switzerland

Received February 5, 2013; Accepted May 16, 2013; Published June 25, 2013

Copyright: (c) 2013 Schulz et al. This is an open-access article distributed under the terms of the Creative Commons Attribution License, which permits unrestricted use, distribution, and reproduction in any medium, provided the original author and source are credited.

Funding: This work was financially supported by the German Research Foundation (DFG), via the Collaborative Research Center SFB 807 (TM) and the Cluster of Excellence 'Macromolecular Complexes' EXC 115 (JDFG and TM), and by a Marsden Grant from the Royal Society of New Zealand (GMC and MIC). Computing resources were in part provided by the Leibniz and Jülich Supercomputing Centers. The funders had no role in study design, data collection and analysis, decision to publish, or preparation of the manuscript.

Competing Interests: The authors have declared that no competing interests exist.

Abbreviations: CCCP, carbonyl cyanide m-chlorophenyl hydrazine; NCD-4, $N$-cyclohexyl- $N^{\prime}$-(4-(dimethylamino)- $\alpha$-naphthyl)-carbodiimide; PMF, proton-motive force; SMF, sodium-motive force; DCCD, $N, N^{\prime}$-dicyclohexylcarbodiimide.

*E-mail: jose.faraldo@biophys.mpg.de (JDF-G); thomas.meier@biophys.mpg.de (TM)

9 These authors contributed equally to this work.

\section{Introduction}

Synthesis of ATP, the most prominent energy source in biological cells, is largely mediated by the ATP synthase, an enzyme that resides in the membranes of bacteria, mitochondria, and chloroplasts. This enzyme catalyzes the phosphorylation of ADP by a rotary mechanism powered by a transmembrane electrochemical gradient, or ion-motive force, of either $\mathrm{H}^{+}$or $\mathrm{Na}^{+}$ (proton-motive force $[\mathrm{PMF}]$ or sodium-motive force $[\mathrm{SMF}]$, respectively). The ATP synthase consists of two sub-complexes: the water-soluble $F_{1}$ sector $[1,2]$, which harbors the catalytic centers, and the membrane-embedded $F_{o}$ complex, which mediates ion translocation across the membrane. These functionally distinct units are mechanically coupled by two additional elements, referred to as central and peripheral stalks [3,4].

In the $\mathrm{F}_{\mathrm{o}}$ sector, eight to 15 copies of subunit $\mathrm{c}$ are assembled into a closed ring [5], which rotates around its axis as ions permeate across the enzyme. The c-ring harbors a series of identical ion-binding sites, typically one per c-subunit, which selectively recognize the coupling ion [6-8]. Ion binding is facilitated by a conserved carboxylic amino acid, usually glutamate; however, it is the neighboring chemical groups in the protein side-chains and backbone, and sometimes a bound water molecule [9-11] that ultimately determine the specificity of the cring binding sites [8]. $\mathrm{Na}^{+}$specific sites typically involve an intricate hydrogen-bonded network of polar groups, while $\mathrm{H}^{+}$binding sites are simpler, and consist mainly of hydrophobic moieties. Either way, one complete rotation of the c-ring results in the translocation of one ion per binding site and the production of three ATP molecules [12,13]; the stoichiometry of the c-ring thus defines the ion-to-ATP ratio of the enzyme, i.e., the minimum ionmotive force required for ATP synthesis [14].

In this study, we characterize the structure, ion specificity, and stoichiometry of the c-ring of the ATP synthase from F. nucleatum, a Gram-negative bacterium implicated in the etiology of periodontal diseases. F. nucleatum grows anaerobically, using amino acids as the preferred carbon source [15]. In particular, glutamate fermentation involves the glutaconyl-CoA decarboxylase, which uses the free energy of decarboxylation to generate a SMF across the cytoplasmic membrane [16,17]. Comparison of the amino-acid sequence of the $F$. nucleatum c-subunit with those of other $\mathrm{Na}^{+}-$ driven ATP synthases suggests that $F$. nucleatum utilizes the SMF 


\section{Author Summary}

Essential cellular processes such as biosynthesis, transport, and motility are sustained by the energy released in the hydrolysis of ATP, the universal energy carrier in living cells. Most ATP in the cell is produced by a membranebound enzyme, the ATP synthase, through a rotary mechanism that is coupled to the translocation of ions across the membrane. The majority of ATP synthases are energized by transmembrane electrochemical gradients of protons (proton-motive force), but a number of organisms, including some important human pathogens, use gradients of sodium ions instead (sodium-motive force). The ion specificity of ATP synthases is determined by a membraneembedded sub-complex, the c-ring, which is the smallest known biological rotor. The functional mechanism of the rotor ring and its variations among different organisms are of wide interest, because of this enzyme's impact on metabolism and disease, and because of its potential for nanotechnology applications. Here, we characterize a previously unrecognized type of $\mathrm{Na}^{+}$-driven ATP synthase from the opportunistic human pathogen Fusobacterium nucleatum, which is implicated in periodontal diseases. We analyzed this ATP synthase and its rotor ring through a multi-disciplinary approach, combining cell-growth and biochemical assays, X-ray crystallography and computersimulation methods. Two crystal structures of the membrane rotor were solved, at low and high $\mathrm{pH}$, revealing an atypical ion-recognition motif mediated by two carboxylate side-chains. This motif is shared by other human pathogens, such as Mycobacterium tuberculosis or Streptococcus pneumonia, whose ATP synthases are targets of novel antibiotic drugs. The implications of this ionrecognition mode on the mechanism of the ATP synthase and the cellular bioenergetics of $F$. nucleatum were thus examined. Our results provide the basis for future pharmacological efforts against this important pathogen.

directly to produce ATP (Figure S1), but this remains to be experimentally demonstrated. Sequence analysis also suggests that ion coordination in the $F$. nucleatum c-ring could involve not only one but possibly two carboxyl side-chains. This is an unusual and interesting feature, shared by other pathogenic bacteria, whose mechanistic implications are unclear. It is conceivable that the second carboxyl group could alter the assumed ion specificity of the c-ring, the ion-to-ATP ratio, or that it confers a novel coupling or regulatory mechanism to the enzyme [18]. It is also unknown what c-subunit stoichiometry is characteristic of $F$. nucleatum. Crystal structures have revealed a wide range of possible stoichiometries in $\mathrm{H}^{+}$-coupled c-rings (reviewed in [5]); whether $\mathrm{Na}^{+}$-dependent c-rings from F-type ATP synthases are similarly diverse is unclear, since to date only one such ring has been characterized structurally at high resolution [6]. To clarify these questions, we have isolated the $F$. nucleatum $\mathrm{F}_{1} \mathrm{~F}_{\mathrm{o}}-\mathrm{ATP}$ synthase, and analyzed its ion-coupling mechanism using microbiological, biochemical, structural and computer-simulation methods, both classical and quantum-mechanical.

\section{Results}

\section{Predicted Structure of the lon-Binding Site in the $F$. nucleatum c-ring}

To gain insights into the ion specificity of the $F$. nucleatum ATP synthase, a structural model of its c-ring was created by homology modeling and molecular dynamics simulations (Figure S2). The structure of the c-ring from Ilyobacter tartaricus was used as template $[6,9]$. The resulting model thus consists of $11 \mathrm{c}$-subunits, with an ion-binding site in between each pair of adjacent subunits. Each of these sites includes two glutamate residues, namely Glu32 and Glu65. Glu65, in the C-terminal helix, is the conserved carboxylate found in other c-subunits. Glu32, in the N-terminal helix, is the additional carboxylate found only in selected species.

The c-ring was initially modeled in the $\mathrm{Na}^{+}$-bound state. To identify the most plausible conformation of the ion-coordination sphere we constructed several models in alternate protonation states of Glu32 and Glu65, and assessed their likelihood using allatom simulations of the complete c-ring in a lipid membrane, as well as quantum-mechanical energy calculations for a reduced model of the binding site. In the first of these models (model A), Glu32 is protonated (in cis) and Glu65 is deprotonated (Figure 1A); in this configuration, the binding site is highly similar to that in the crystal structure of the $I$. tartaricus c-ring $[6,9]$, except that in that structure Glu32 is replaced by glutamine. $\mathrm{Na}^{+}$is coordinated directly by oxygen atoms in the side-chains of Glu65, Glu32, and Ser66, as well as by the backbone carbonyl of Val63 and a bound water molecule, which also interacts with Thr67. The proton bound to Glu32 mediates a hydrogen bond to Glu65, which is the acceptor of two more hydrogen bonds, donated by Tyr70 and Ser66. In a second model (model B), Glu32 is deprotonated while Glu65 is protonated (initially in cis). In simulation, this model evolves in time towards a conformation similar to that in model A, with the bound proton (which switches to trans) donating a hydrogen bond to Glu32, and $\mathrm{Na}^{+}$penta-coordinated (Figure 1B). Lastly, in a third model (model C), both Glu32 and Glu65 were set in the deprotonated state (Figure 1C). This configuration leads to a noticeably different conformation of the binding site, in which only Glu32 and Ser66 coordinate the $\mathrm{Na}^{+}$ion, while Glu65 is displaced outwards and the bound water molecule reorients.

To determine whether model $\mathrm{A}$ is more or less probable than model $\mathrm{B}$, we assessed the energetics of proton transfer between Glu32 and Glu65 using Hartree-Fock quantum-mechanical calculations (Figure 2A). These calculations demonstrate that model $\mathrm{A}$ is more energetically favorable than model $\mathrm{B}$, by about $10 \mathrm{kcal} / \mathrm{mol}$. That is, if a proton were to be bound to the site, it would be localized on Glu32. To determine whether model A is more or less probable than model C, i.e., whether a proton indeed resides in the binding site along with $\mathrm{Na}^{+}$, we carried out a calculation of the $\mathrm{pK}_{\mathrm{a}}$ of Glu32, in the context of the complete cring with bound $\mathrm{Na}^{+}$, using Free-Energy Perturbation (FEP) simulations. This calculation shows that the $\mathrm{pK}_{\mathrm{a}}$ of Glu32 is markedly shifted upwards, relative to its intrinsic value in solution (Figure 2B). Thus, we conclude that in the membrane-embedded, $\mathrm{Na}^{+}$-loaded binding sites of the $F$. nucleatum c-ring, Glu32 is protonated under physiological conditions. Our predicted structure of the $\mathrm{Na}^{+}$-bound state is therefore that in model A; i.e., both a sodium ion and a proton are concurrently bound to the same binding site, with the $\mathrm{H}^{+}$bound to Glu32.

\section{Predicted lon Selectivity of the $F$. nucleatum c-ring}

The ion selectivity of c-rings in which only one ion can occupy the binding sites is defined by the difference in the binding freeenergy of either $\mathrm{H}^{+}$or $\mathrm{Na}^{+}[8,19,20]$. Because in the $F$. nucleatum cring one additional $\mathrm{H}^{+}$resides in the binding site in the $\mathrm{Na}^{+}$state, the analogous free-energy difference is that between a state with two $\mathrm{H}^{+}$bound and another with one $\mathrm{Na}^{+}$and one $\mathrm{H}^{+}$. Thus, to examine the question of whether the $F$. nucleatum ATP synthase is driven by a SMF or a PMF, we re-modeled and simulated the structure of the c-ring with two $\mathrm{H}^{+}$bound to Glu65 and Glu32, respectively (Figures 3A and S2), and used additional free-energy 

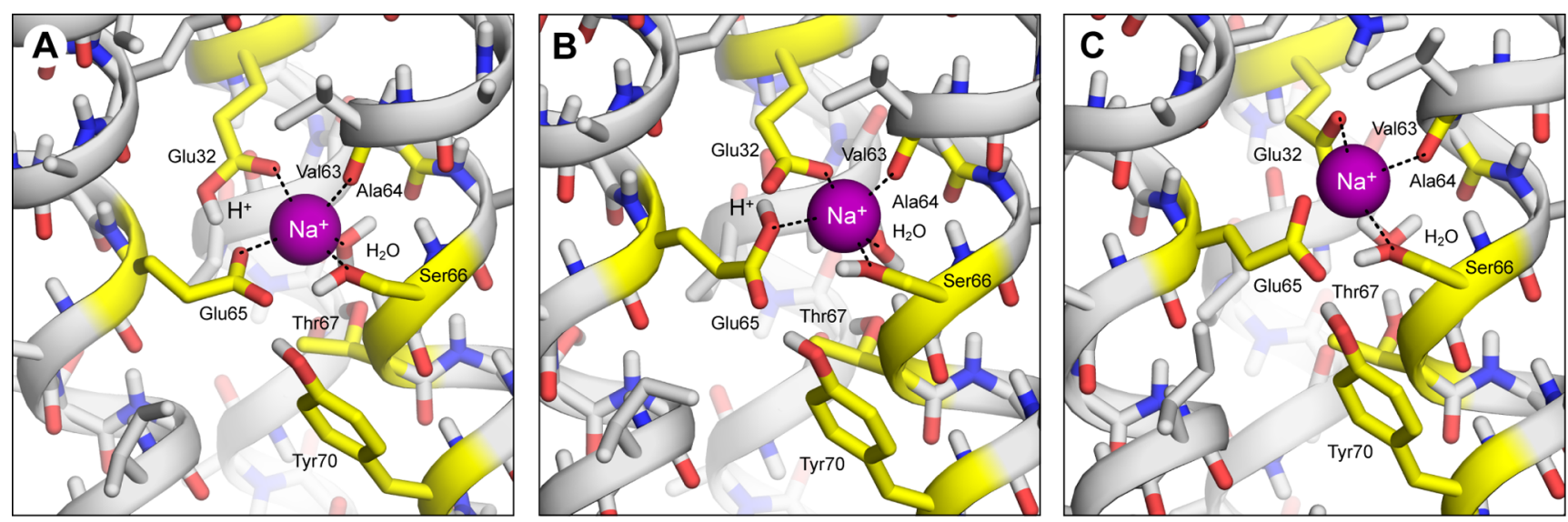

Figure 1. Alternative models of the ion-binding sites in the $F$. nucleatum c-ring, with $\mathrm{Na}^{+}$bound. The ion-coordinating groups in the protein are indicated with dashed lines. Hydrogen atoms in non-polar groups are omitted for clarity. (A) Model with Glu32 protonated in cis and Glu65 in the deprotonated state (model A), predicted to be the most likely (see Results). (B) Model with Glu32 deprotonated and Glu65 protonated (model B). In this model, the proton bound to Glu65 was initially modeled in cis, as this is the most probable geometry for the isolated side-chain. However, within 250 ps of the start of the simulation, the carboxyl group of Glu65 switched to trans. (C) Model with Glu32 and Glu65 in the deprotonated state (model C). During the simulation of this model, the electrostatic repulsion between Glu32 and Glu65 caused the latter to displace outwards, away from the $\mathrm{Na}^{+}$ion, which becomes coordinated by Glu32 in a bi-dentate configuration. Note the bound water reorients and no longer contributes to $\mathrm{Na}^{+}$coordination.

doi:10.1371/journal.pbio.1001596.g001

calculations to assess the likelihood of this doubly protonated state, relative to a state with one $\mathrm{Na}^{+}$and one $\mathrm{H}^{+}$bound to the site.

Figure 3B shows the computed free energy of selectivity of the $F$. nucleatum rotor in reference to other c-rings characterized previously $[11,19,20]$. Two alternative models of the $\mathrm{H}^{+}$-bound state were considered (Figures 3A and S2), differing on whether the structural water molecule present in the $\mathrm{Na}^{+}$-bound state is included in the site or not. In both cases, the calculations show that the specificity of the $F$. nucleatum c-ring is in stark contrast to that of $\mathrm{H}^{+}$-driven ATP synthases. For example, relative to the c-ring of $B$. pseudofirmus $\mathrm{OF} 4$, the selectivity for $\mathrm{H}^{+}$of the $F$. nucleatum c-ring is drastically diminished in favor of $\mathrm{Na}^{+}$, by about $26 \mathrm{kcal} / \mathrm{mol}$, i.e., more than ten orders of magnitude (Figure 3B). Instead, the computations indicate that the ion specificity of the $F$. nucleatum rotor is comparable to that of the V-type ATPase from Enterococcus hirae, which has been experimentally shown to be very weakly $\mathrm{H}^{+}$ selective [21]. In particular, the $F$. nucleatum c-ring is more selective for $\mathrm{H}^{+}$and opposed to $\mathrm{Na}^{+}$than that of E. hirae, by $\sim 1-3 \mathrm{kcal} /$ mol, i.e., up to $\sim 100$-fold. Nevertheless, because in the physiological environment of $F$. nucleatum (i.e., the human mouth flora) $\mathrm{Na}^{+}$is in excess over protons at least by five orders of magnitude, our prediction is therefore that one $\mathrm{Na}^{+}$and one $\mathrm{H}^{+}$, rather than two $\mathrm{H}^{+}$, will typically occupy the ion-binding sites of the $F$. nucleatum c-ring. For the same reason the $E$. hirae ATPase functions as a $\mathrm{Na}^{+}$pump under physiological conditions. Thus, we conclude that in $F$. nucleatum the SMF is used to drive ATP synthesis directly.

\section{Effect of lonophores and Related Inhibitors on $F$. nucleatum Growth}

To begin to assess the specificity of $F$. nucleatum ATP synthase experimentally, we first tested the effect of various protonophores, ionophores, and ATP synthase inhibitors on anaerobic growth (Figure S4). Growth was inhibited by the protonophores carbonyl cyanide m-chlorophenylhydrazone (CCCP), 2,4-dinitrophenol (DNP), and 3,3', $4^{\prime}, 5$-tetrachlorosalicylanilide (TCS), but the sensitivity to these agents varied, with TCS being the most potent. Monensin, a monovalent cation ionophore, was also a potent growth inhibitor of $F$. nucleatum. Amiloride and its more hydrophobic derivative 5 -( $\mathcal{N}$-ethyl- $\mathcal{N}$-isopropyl) amiloride (EIPA), are blockers of $\mathrm{Na}^{+}$channels and $\mathrm{Na}^{+} / \mathrm{H}^{+}$antiporters, and both compounds inhibited the growth of $F$. nucleatum. The membranepermeable ATP synthase inhibitor $\mathcal{N}, \mathcal{N}^{\prime}$-dicyclohexylcarbodiimide (DCCD) also inhibited growth, but tributyltin chloride (TBT-Cl) had no significant effect (Figure S5). Taken together, these data demonstrate that $F$. nucleatum cells require both a PMF and a SMF to grow, and that classical ATP synthase inhibitors slow down growth. However, these data do not clarify whether the $F$. nucleatum ATP synthase utilizes the PMF or the SMF to sustain ATP production.

\section{Characterization of the $F$. nucleatum ATP Synthase}

To clarify what energy source is utilized by the $F$. nucleatum ATP synthase, we set out to specifically characterize the enzyme, both in inverted membrane vesicles from $F$. nucleatum and purified. The ATP hydrolysis activity of the inverted membranes was in the range $0.09-0.15$ units $/ \mathrm{mg}$ protein $(1$ unit $=1 \mu \mathrm{mol}$ ATP hydrolyzed/min), and exhibited a weak $\mathrm{pH}$ dependence, with a $\mathrm{pH}$ optimum of 7.5-8.5 (Figure S6A). This ATPase activity was strongly inhibited by DCCD (unpublished data), which covalently modifies the carboxyl side-chain of the c-ring ion-binding sites (here Glu65). ATP synthesis in inverted membrane vesicles could be driven by a SMF and under these conditions ATP synthesis was sensitive to both the sodium ionophore monensin and DCCD (Figure S6B). No significant ATP synthesis could be detected in the absence of $\mathrm{Na}^{+}$, even in the presence of a valinomycin-induced $\mathrm{K}^{+}$ diffusion potential. However, a chemical gradient of $\mathrm{Na}^{+}$was not sufficient to drive ATP synthesis in the absence of a membrane potential. These data support the presence of a $\mathrm{Na}^{+}$-coupled Ftype ATP synthase in membrane vesicles of $F$. nucleatum.

We next purified the ATP synthase, ultimately achieving a 38fold purification (Table S1). Silver-stained SDS-gels and MALDI were used to confirm that all constituent subunits were present in the purified sample (Figure S7). The ATPase activity of the purified enzyme was stable over several days (Figure S8A). The apparent $\mathrm{K}_{\mathrm{m}}$ for $\mathrm{Mg}^{2+}$ and ATP were $0.64 \mathrm{mM}$ and $0.25 \mathrm{mM}$, 

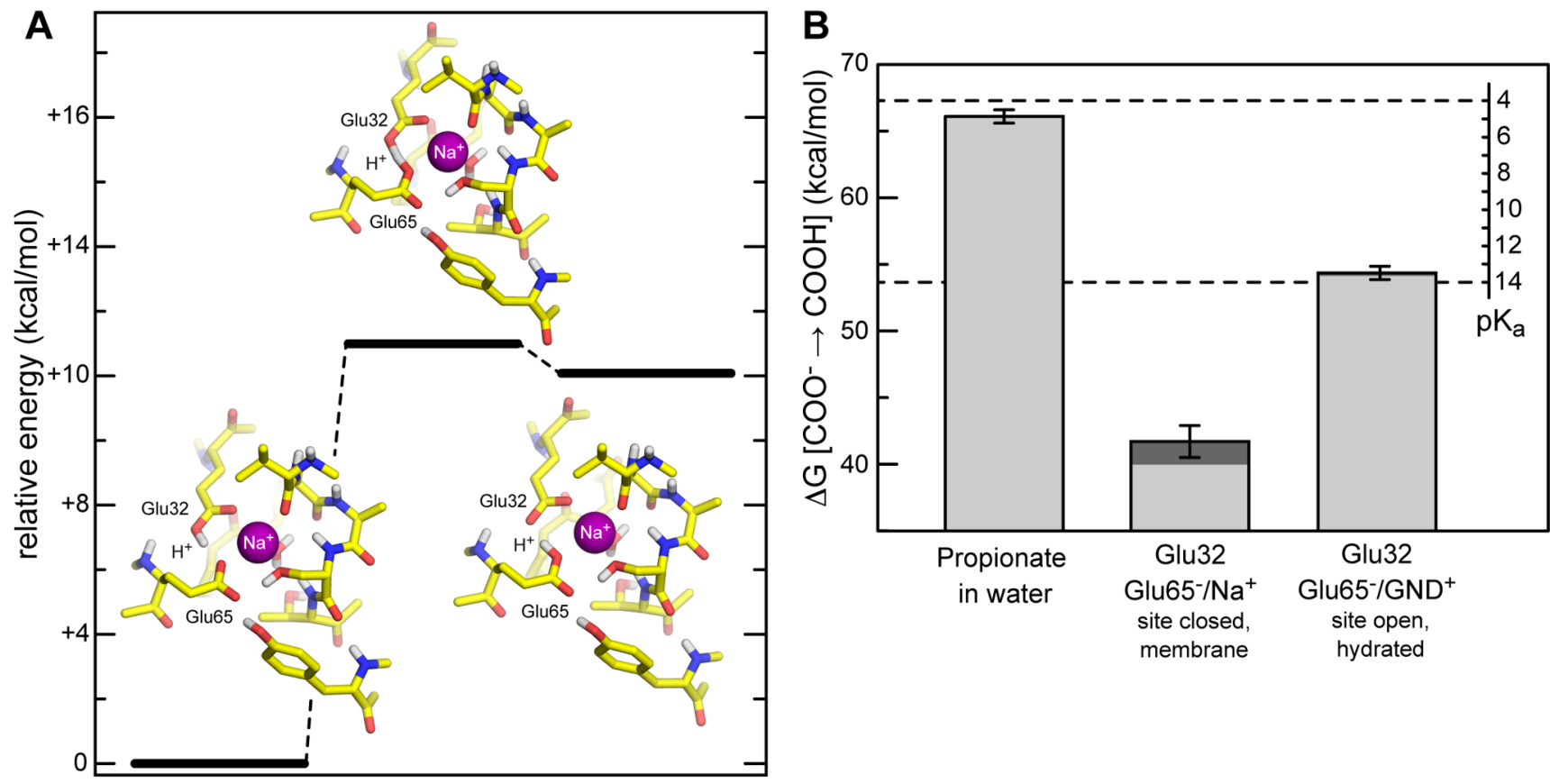

Figure 2. Likelihood of protonation of the $\mathrm{Na}^{+}$-loaded binding sites in the $F$. nucleatum c-ring, and most probable configuration. (A) Energetics of proton transfer between Glu65 and Glu32 (models A and B in Figure 1), with a $\mathrm{Na}^{+}$concurrently bound, based on Hartree-Fock quantum-mechanical calculations for a reduced model of the binding site. The potential energy values plotted correspond to the optimized geometries in each case. The geometry and potential energy of the transition state are also provided. (B) Calculated free-energy gain associated with the protonation of Glu32, relative to a side-chain analog in solution (propionate); the formation energy of the chemical bond is omitted, as this is expected to be constant. Calculated values are translated into a $\mathrm{pK}_{\mathrm{a}}$ scale, by setting the free-energy value for propionate to its $\mathrm{known}^{\mathrm{pK}} \mathrm{a}$ value, i.e., 4.9. The protonation of Glu32 is studied either in the $\mathrm{Na}^{+}$-bound, closed conformation of the c-ring binding sites (Figure $1 \mathrm{~A}$ ); or in an open, hydrated conformation (Figure 9). In both cases, to the values calculated by FEP/MD (light grey) we added a correction calculated with Poisson electrostatic theory on account of the membrane polarizability (dark grey).

doi:10.1371/journal.pbio.1001596.g002

respectively (Figure S8B-S8C). $\mathrm{CaCl}_{2}$ could not replace $\mathrm{MgCl}_{2}$, since no activity was detected at increasing concentrations of $\mathrm{CaCl}_{2}$ (unpublished data).

Two cornerstone properties of all $\mathrm{Na}^{+}$-coupled ATP synthases are the ability to be specifically stimulated by low amounts of $\mathrm{Na}^{+}$(or $\mathrm{Li}^{+}$), and the protective effect of $\mathrm{Na}^{+}$against DCGD inhibition $[22,23]$. Both these properties were apparent in the $F$. nucleatum ATP synthase (Figures 4 and 5). While $\mathrm{K}^{+}$had no stimulatory effect on the ATPase activity, $\mathrm{Na}^{+}$(and $\mathrm{Li}^{+}$) stimulated maximally at low millimolar concentrations (Figure 4A), both at neutral and high $\mathrm{pH}$ (Figure 4B). The ATPase activity of the enzyme was inhibited by DCCD in a concentration-dependent manner (Figure S9). However, even with high concentrations of DCCD $\left(400 \mu \mathrm{M}\right.$ ), $50 \mathrm{mM} \mathrm{Na}^{+}$(or $50 \mathrm{mM} \mathrm{Li}^{+}$, but not $\mathrm{K}^{+}$) strongly protected the enzyme from inhibition (Figure 5). The protective effect of $\mathrm{Na}^{+}$was most apparent at lower $\mathrm{pH}$ values, consistent with the fact that DCCD modification requires protonation of Glu65. These observations are strongly indicative of a specific binding site for $\mathrm{Na}^{+}$in the c-ring of the $F$. nucleatum ATP synthase.

\section{Evidence of $\mathrm{Na}^{+}$Binding to the Isolated F. nucleatum c- ring}

We next purified the $F$. nucleatum c-ring using a novel heterologous expression system in Escherichia coli DK8 cells, which synthesizes a hybrid $\mathrm{F}_{1} \mathrm{~F}_{\mathrm{o}}$-ATP synthase with subunits $\mathrm{F}_{1}$-ab $\mathrm{b}_{2}$ from I. tartaricus and the c-ring from $F$. nucleatum. From this hybrid $\mathrm{F}_{1} \mathrm{~F}_{\mathrm{o}}$ complex we isolated the c-ring, which migrates at $\sim 51 \mathrm{kDa}$ on an SDS-polyacrylamide gel, disintegrating into c-monomers only upon tricholoroacetic acid (TCA) treatment (Figure S10). The expected mass of $F$. nucleatum c-subunit was confirmed by mass spectrometry (Figure S11).

To address the question of ion specificity, we exposed detergentsolubilized c-rings to $\mathcal{N}$-cyclohexyl- $\mathcal{N}^{\prime}$-(4-(dimethylamino)- $\alpha$-naphthyl)-carbodiimide (NCD-4), a fluorescent DCCD analogue, in the absence and presence of $\mathrm{Na}^{+}$at $\mathrm{pH}$ 5.7. The reaction of NCD-4 with the c-ring resulted in a continuous increase of fluorescence (Figure 6). The reaction stopped immediately upon addition of only $15 \mathrm{mM} \mathrm{NaCl}$, but continued linearly in a separate long-term control experiment in the absence of $\mathrm{NaCl}$ (Figure S12). These data indicate that NCD-4 modifies Glu65 in the isolated c-ring, and that $\mathrm{Na}^{+}$ions inhibit this reaction, in clear contrast to similar measurements for $\mathrm{H}^{+}$-coupled c-rings, in which $\mathrm{Na}^{+}$had no effect $[8,10]$. The rapid protective effect of $\mathrm{Na}^{+}$demonstrates that ions can access the binding sites of detergent-solubilized c-rings in less than a few seconds (pipetting time), consistent with a previous report for an analog fluorescent inhibitor [24]. It is also worth mentioning that the migration of intact and monomerized (TCAtreated) c-ring samples on an SDS-polyacrylamide gel, exposed to UV light, was significantly reduced after NCD-4 modification (Figure S13), indicating that NCD-4 becomes covalently bound to the c-ring.

\section{High-Resolution Structure of the $F$. nucleatum $c_{11}$ Ring}

To obtain structural evidence of a $\mathrm{Na}^{+}$-binding site in the $F$. nucleatum ATP synthase, we solved the atomic structure of its c-ring by X-ray crystallography. Crystals of the $\mathrm{c}_{11}$ ring were first grown at $\mathrm{pH} 5.3$ and one of the crystals yielded a complete $2.2 \AA$ dataset 
A

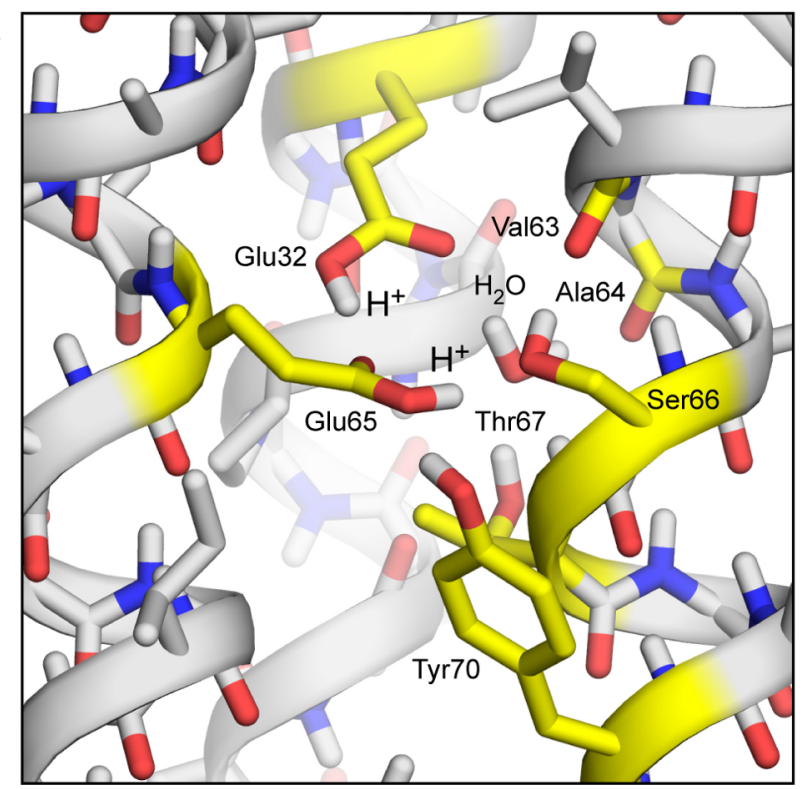

B

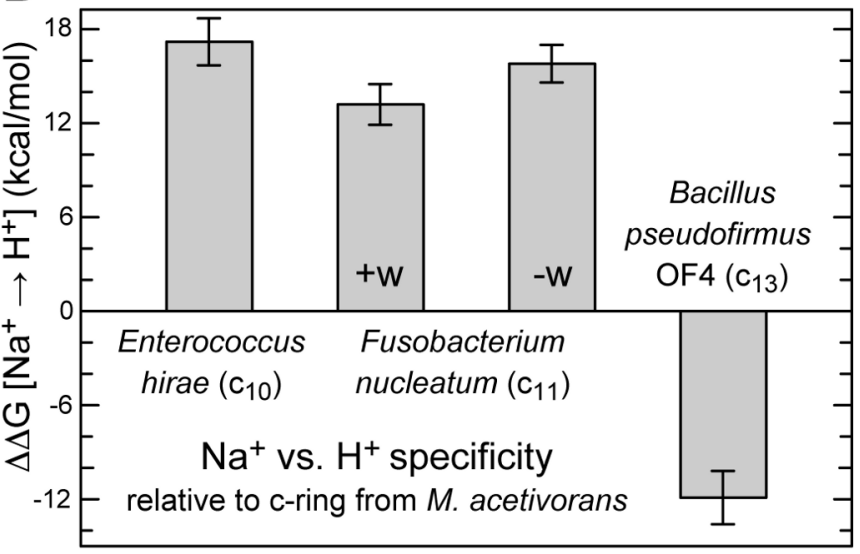

Figure 3. Calculated ion selectivity of the $\boldsymbol{F}$. nucleatum c-ring. (A) Predicted structure of the ion binding sites in the absence of $\mathrm{Na}^{+}$, with two $\mathrm{H}^{+}$bound. Hydrogen atoms in non-polar groups are omitted for clarity. Note the binding site harbors two $\mathrm{H}^{+}$, one bound to Glu32 and another to Glu65 (both in cis). Two alternative configurations, one of which lacks a bound water molecule, are also shown in Figure S3. (B) Calculated free-energy of selectivity for $\mathrm{H}^{+}$vs. $\mathrm{Na}^{+}$of the $F$. nucleatum c-ring binding sites, relative to other c-rings previously characterized. The $\mathrm{Na}^{+}$state is that rendered in Figure $1 \mathrm{~A}$; note the bound water molecule. Two possible $\mathrm{H}^{+}$-bound states are considered, in which the water molecule is either preserved (+w), as in Figure $3 \mathrm{~A}$, or removed $(-\mathrm{w})$, as in Figure $\mathrm{S} 3 \mathrm{~B}$. doi:10.1371/journal.pbio.1001596.g003

(Table S2). In this crystal, one asymmetric unit contains two complete c-rings. Like the c-ring from $I$. tartaricus [6], the $F$. nucleatum rotor is made by 11 identical c-subunits (Figure 7). Each c-subunit consists of two transmembrane $\alpha$-helices connected by a short loop, which would face the cytoplasmic side of the membrane; both $\mathrm{N}$ - and C-termini would therefore be in the periplasmic space. In the crystal, lattice contacts are established between the hydrophilic C-termini and the short loop.

The $\mathrm{c}_{11}$ ring is $\sim 68 \AA$ in height and its outermost diameter, towards the cytoplasmic side, is $\sim 52 \AA$ (Figure 7). The diameter of the ring is smallest at its middle $(\sim 40 \AA)$, i.e., at the level of the ion-binding sites, and therefore its shape resembles an hourglass. The transmembrane region of the protein appears to extend from Tyr80 to Ser55 on the periplasmic and cytoplasmic sides, respectively (Figure 8A). Within these limits, the c-ring surface is highly hydrophobic, while polar and charged amino acids are predominantly found on the surface facing the cytoplasm, as well as at the $\mathrm{N}$ - and C-termini. Like other c-rings, the F. nucleatum $\mathrm{c}_{11}$ ring features an inner pore (Figure $7 \mathrm{~B}$ ), mostly lined by hydrophobic residues. Detergent molecules can also be discerned on the periplasmic entrance of the pore, suggesting that this pore would be blocked by phospholipids (Figure S2B) in vivo. According to the mass spectrometry analysis (Figure S11), a small fraction of the c-subunits in our preparation is formylated at the $\mathrm{N}$ termini, but apparently not in sufficient amounts to yield enough electron density from the diffraction data.

The c-ring was crystallized in the presence of near-physiological concentrations of $\mathrm{Na}^{+}(100 \mathrm{mM})$. To confirm the location of the $\mathrm{Na}^{+}$-binding sites, we calculated an omit electron-density map (Figure 7). This map reveals 11 binding sites, each located at one of the interfaces between c-subunits. A close-up view of these sites reveals an interaction network of several amino acids around the central density caused by $\mathrm{Na}^{+}$(Figure 8B; Table 1). The arrangement of the $\mathrm{Na}^{+}$-binding site is highly similar to that in the $I$. tartaricus $\mathrm{c}_{11}$ ring $[6,9]$. The most notable difference is the presence of a second glutamate side-chain, Glu32, in addition to the conserved Glu on the C-terminal helix (Glu65). Both sidechains contribute to $\mathrm{Na}^{+}$coordination, via one oxygen atom of each carboxyl group. The other two oxygen atoms are at hydrogen-bonding distance of $\sim 2.7 \AA$ from each other (Table 1). This arrangement suggests that a proton is bound to the site in addition to $\mathrm{Na}^{+}$, consistent with the free-energy calculations described above (Figure 2). In addition to Glu32 and Glu65, Ser66:O $\gamma$ and Val63:O from the adjacent c-subunit also contribute to $\mathrm{Na}^{+}$coordination. Ser66:O $\gamma$ and Tyr70:OH also interact with Glu65, as hydrogen-bond donors, stabilizing the socalled ion-locked conformation of the site [6]. Finally, electron density for a water molecule is found within coordinating distance from the ion, with Thr67:O $\gamma$ and Ala64:O as potential hydrogenbond acceptors.

We also investigated the influence of the environmental $\mathrm{pH}$ on the conformational state of the ion-binding site, by crystallizing the $F$. nucleatum $\mathrm{c}_{11}$ ring in $\mathrm{NaOH}$-titrated buffer at pH 8.7. The resulting structure, at $2.6 \AA$ resolution (Table 1), revealed again a locked conformation of the binding site identical to that at $\mathrm{pH} 5.3$, with $\mathrm{Na}^{+}$and $\mathrm{H}^{+}$bound concurrently (Figure 8). As we observed in previous structural studies of c-rings [10,25], the detergent used in these crystals provides a hydrophobic belt that effectively uncouples the binding sites from the $\mathrm{pH}$ or $\mathrm{Na}^{+}$concentration conditions in the crystallization buffer, in a manner that likely resembles the shielding effect of a lipid membrane.

\section{Is the Additional $\mathrm{H}^{+}$Bound to the c-ring Co-transported} with $\mathrm{Na}^{+}$?

The finding that one $\mathrm{Na}^{+}$and one $\mathrm{H}^{+}$can concurrently occupy the binding sites in the $F$. nucleatum $\mathrm{c}_{11}$ ring raises the possibility that both ions are co-transported across the membrane as the ring 

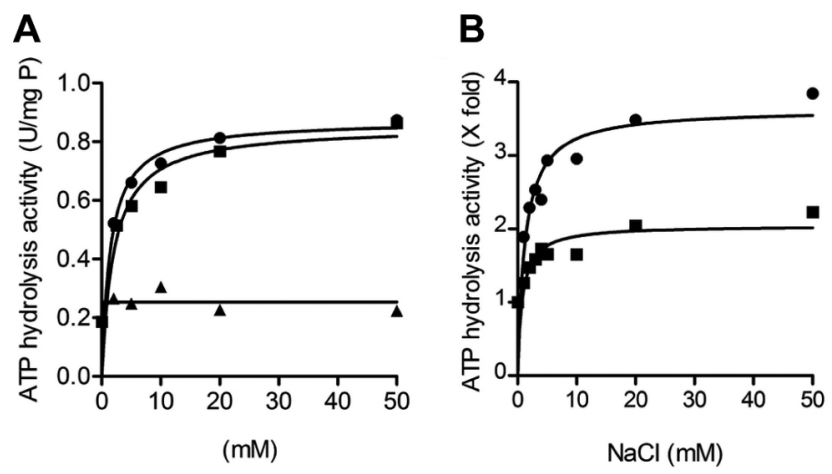

Figure 4. Catalytic activity of the purified $F_{1} F_{0}-A T P$ synthase from F. nucleatum. (A) Activation of the $F$. nucleatum ATP synthase by $\mathrm{Na}^{+}, \mathrm{Li}^{+}$, and $\mathrm{K}^{+}$ions $\left(\mathrm{Na}^{+}, \mathbf{O} ; \mathrm{Li}^{+}, \mathbf{\square}\right.$; and $\left.\mathrm{K}^{+}, \mathbf{\Delta}\right)$. (B) Activation of the ATP synthase by $\mathrm{Na}^{+}$ions at $\mathrm{pH} 7.5(\mathbf{)}$ ) and $\mathrm{pH} 9.0$ (更). The ATP hydrolysis activity was determined using the ATP-regenerating assay $(120-140 \mu \mathrm{g}$ protein), at $37^{\circ} \mathrm{C}$. Activity in units $/ \mathrm{mg}$ of protein ( 1 unit $=1 \mu \mathrm{mol}$ ATP hydrolysed/min). $100 \%$ of activity corresponds $1-2$ units $/ \mathrm{mg}$ at $\mathrm{pH} 7.5$ and $0.6-0.72$ units $/ \mathrm{mg}$ at $\mathrm{pH}$ 9.0. The assay mixture contained $50 \mathrm{mM}$ MOPS, $2 \mathrm{mM} \mathrm{MgCl} 2$ (pH 7.5) in (A) and $50 \mathrm{mM}$ MES-MOPS-Tris, $2 \mathrm{mM}$ $\mathrm{MgCl}_{2}$ in (B). The values plotted are representative of at least two biological replicates; the statistical variance was less than $20 \%$. doi:10.1371/journal.pbio.1001596.g004

rotates. This would imply that ATP synthesis in F. nucleatum is not only coupled to the SMF, but also to the PMF. More generally, the implication for other c-rings whose ion-binding sites include two carboxyl groups would be an ion-to-ATP ratio that is twice larger than what the c-subunit stoichiometry indicates (here 22/3 instead of $11 / 3)$.

In the operating enzyme, ion loading and release from the cring occurs when each of the c-subunits encounters the interface with the adjacent subunit-a, as the ring rotates within the membrane. No high-resolution structural data are available for subunit-a or its interface with the c-ring, but this interface is reportedly well hydrated [26,27]. We have previously shown that hydration is sufficient to facilitate the reversible gating of the csubunit binding sites, and to enable binding and unbinding of ions $[25,28]$. In the open, ion-free state, the conserved glutamate projects away from the ring [25,28,29] and is believed to transiently engage a conserved arginine side-chain in the fourth transmembrane helix of subunit-a [30,31].

From an electrostatic standpoint, the likelihood of concurrent release of $\mathrm{Na}^{+}$and $\mathrm{H}^{+}$from the $F$. nucleatum ring would be maximal in this hypothetical transient state, since negatively charged Glu65 would be more distant from Glu32 than in the closed state, while still being neutralized by the key arginine in subunit-a, instead of the bound $\mathrm{Na}^{+}$. To clarify whether the likelihood of this event is significant, we created an idealized structural model of this intermediate configuration (Figure 9). We then re-computed the $\mathrm{pK}_{\mathrm{a}}$ of Glu32 using FEP simulations. As shown in Figure 2B, the upward shift in the calculated $\mathrm{pK}_{\mathrm{a}}$ of Glu32 in this open, hydrated state is indeed significantly smaller than in the closed state, but nevertheless deprotonation remains very unlikely. This result implies that only $\mathrm{Na}^{+}$would be released from the c-ring, and therefore translocated across the membrane, while the additional $\mathrm{H}^{+}$are constitutively bound to the structure.

To validate this conclusion experimentally, we examined the extent of proton uptake into inverted membrane vesicles from $F$. nucleatum and $E$. coli cells, driven by their respective ATP synthases, functioning in the ATP hydrolysis direction (see Methods). As expected, addition of ATP to the $E$. coli membranes resulted in the quenching of the fluorescence $\mathrm{pH}$ reporter acridine orange, due to $\mathrm{H}^{+}$accumulation inside the vesicles (Figure 10A). This quenching was reversed by the addition of CCCP demonstrating that a $\mathrm{pH}$ gradient was indeed present. However, no discernible quenching was detected for $F$. nucleatum, under conditions in which its ATP synthase is active in hydrolysis. Specifically we tested buffers with $\mathrm{Na}^{+}$concentrations of $\sim 2 \mathrm{mM}$ and $10 \mathrm{mM}$, at $\mathrm{pH}$ values of 6 (Figure 10B and 10C) or lower (unpublished data). Under these conditions we expect ATP hydrolysis to be coupled to $\mathrm{Na}^{+}$uptake into the vesicles, based on the above mentioned activity and inhibition measurements for both the purified enzyme (Figures 4 and 5) and the c-ring (Figure 6), and the fact that ATP synthesis in these membrane vesicles is $\mathrm{Na}^{+}$-dependent and sensitive to monensin (Figure S6B). However, proton co-transport was not detected in any case.

In sum, computations and measurements demonstrate that the protons that occupy the ion-binding sites in the F. nucleatum c-ring, concurrently with $\mathrm{Na}^{+}$, remain bound to the structure throughout
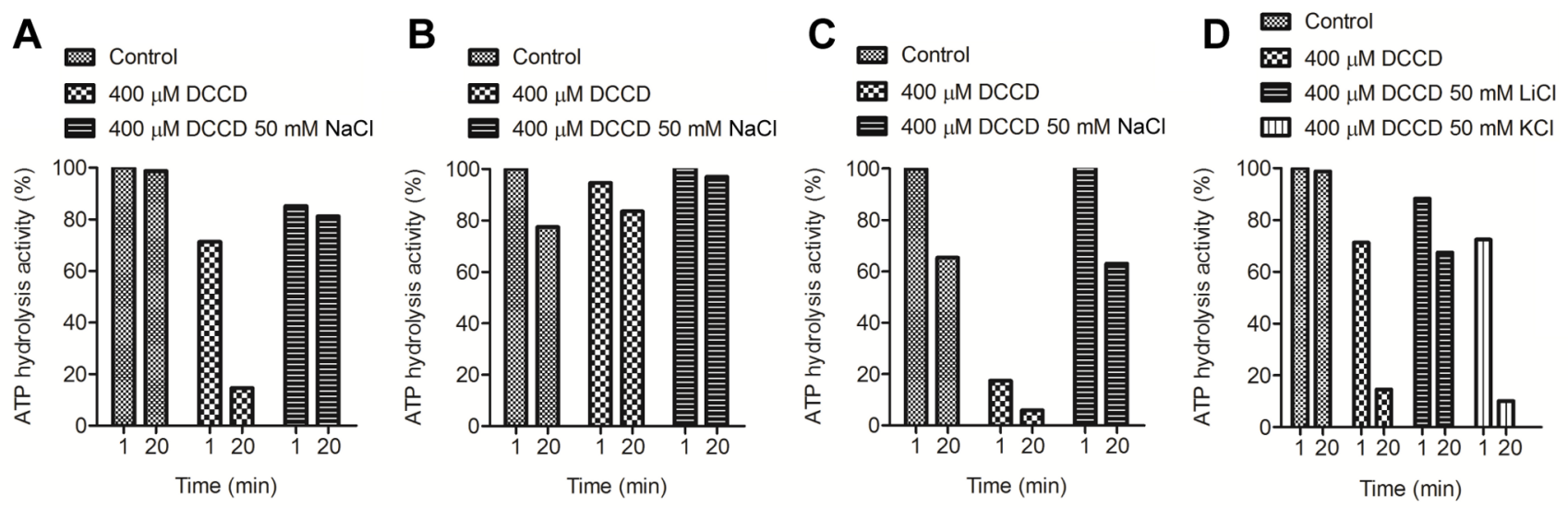

Figure 5. Protective effect of $\mathrm{Na}^{+}$and $\mathrm{Li}^{+}$against $\mathrm{DCCD}$ inhibition of the purified $F$. nucleatum ATP synthase. The purified protein (120$140 \mu \mathrm{g}$ ) was incubated at $25^{\circ} \mathrm{C}$ for $20 \mathrm{~min}$ in the presence of either $400 \mu \mathrm{M} \mathrm{DCCD}$ or $400 \mu \mathrm{M} \mathrm{DCCD}$ and $50 \mathrm{mM}$ NaCl in $50 \mathrm{mM}$ MES-MOPS-Tris, $2 \mathrm{mM}$ $\mathrm{MgCl}_{2}$, (A) at pH 7.5, (B) at pH 9, and (C) at pH 6.5. (D) NaCl was substituted by either LiCl or KCl in $50 \mathrm{mM} \mathrm{MES}-\mathrm{MOPS}-\mathrm{Tris}^{2} 2 \mathrm{mM} \mathrm{MgCl}$, $\mathrm{pH} 7.5 .100 \%$ enzyme activity corresponds to $1-2$ units/mg of protein. The values plotted are representative of at least two to three individual experiments; the statistical variance was less than $20 \%$.

doi:10.1371/journal.pbio.1001596.g005 


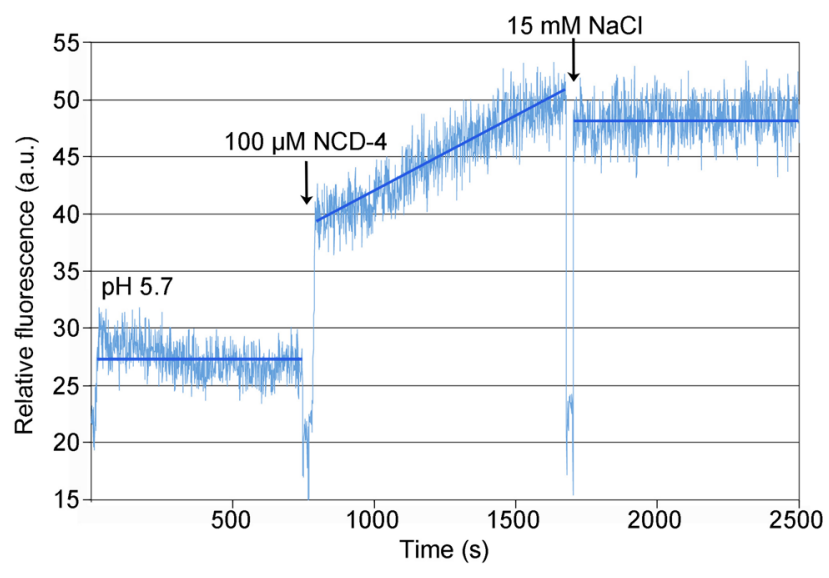

Figure 6. Kinetics of NCD-4 modification of detergent-solubilized c-rings from $F$. nucleatum. $100 \mu \mathrm{M}$ NCD-4 was added to a sample of purified $F$. nucleatum $\mathrm{c}_{11}$ ring in MES buffer $(\mathrm{pH}$ 5.7) and $1.5 \%$ $(w / v) n$-octyl- $\beta$-D-glycoside. A continuous increase in fluorescence was measured upon reaction of NCD-4 with Glu65. Addition of $15 \mathrm{mM} \mathrm{NaCl}$ precluded further increase in the fluorescence. An extended control measurement, with no $\mathrm{NaCl}$ added, is shown in Figure $\mathrm{S} 12$. doi:10.1371/journal.pbio.1001596.g006

the rotation of the ring, and therefore are not co-translocated with $\mathrm{Na}^{+}$across the membrane.

\section{Discussion}

Mechanistic Implications of the Two-Carboxylate IonBinding Motif

We describe the structure of a novel type of $\mathrm{Na}^{+}$-binding site in the c-ring of the $\mathrm{F}_{1} \mathrm{~F}_{\mathrm{o}}$-ATP synthase from $F$. nucleatum and demonstrate that this enzyme is physiologically coupled to the SMF. The c-ring features two glutamate residues in each of its 11 ion-binding sites, instead of a single carboxylate side-chain as is typical. While such a motif has been observed in other $\mathrm{Na}^{+}$binding proteins, and had been anticipated for c-rings in particular $[9,18]$, the implications in regard to the mechanism of ion transport and the specificity of the enzyme were unclear. A previous biochemical study of the PMF-driven ATP synthase from $E$. coli analyzed mutants with a two-carboxylate motif in the c-ring proton-binding sites, concluding that the engineered carboxylate (Asp24), which replaces a hydrophobic side-chain (Ala24), must be protonated for the enzyme to function, while it is the aspartate side-chain found in the wild-type enzyme (Asp61) that likely mediates $\mathrm{H}^{+}$translocation [32]. The substitution of Ala24 by Asp or Glu, however, induces a $\mathrm{pH}$ dependence on the $\mathrm{H}^{+}$transport activity in the physiological $\mathrm{pH}$ range, not observed for the wildtype enzyme. In a subsequent study of the two-carboxylate $E$. coli mutants, this dependence led to the proposal that the second carboxylate found in the binding sites of some c-rings might function as a regulatory high-pH sensor to inhibit the iontranslocation mechanism [18]. In light of our results, however, we interpret this $\mathrm{pH}$ dependence differently. In our view, it likely reflects a down-shift in the overall $\mathrm{p} K_{\mathrm{a}}$ of the proton-binding sites in the mutagenized $E$. coli c-ring, as a result of the constitutive protonation of the added carboxylic side-chain, which naturally diminishes the affinity for a second proton (i.e., the one transported across the membrane), relative to the wild-type. This interpretation would also be consistent with the diminished rate of $\mathrm{H}^{+}$translocation mediated by these two-carboxylate mutants. In support of our hypothesis that the second carboxylate group is constitutively protonated, we find that under physiological conditions the $F$. nucleatum ATP synthase mediates the translocation of $\mathrm{Na}^{+}$only, i.e., protons are not co-transported during either
A

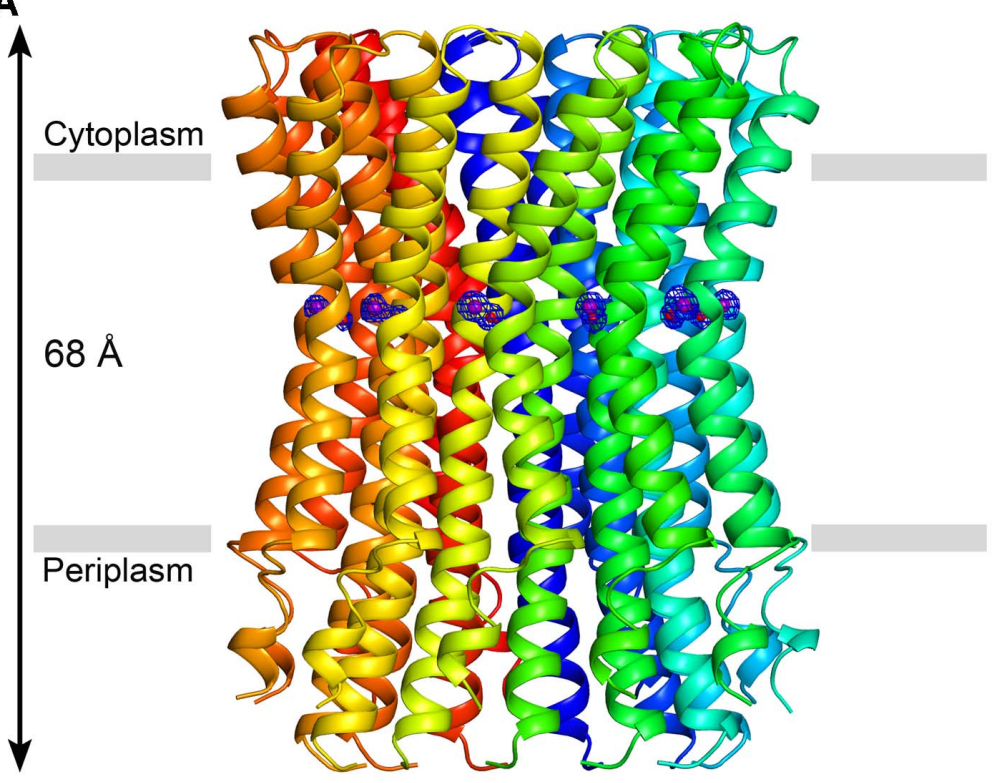

B

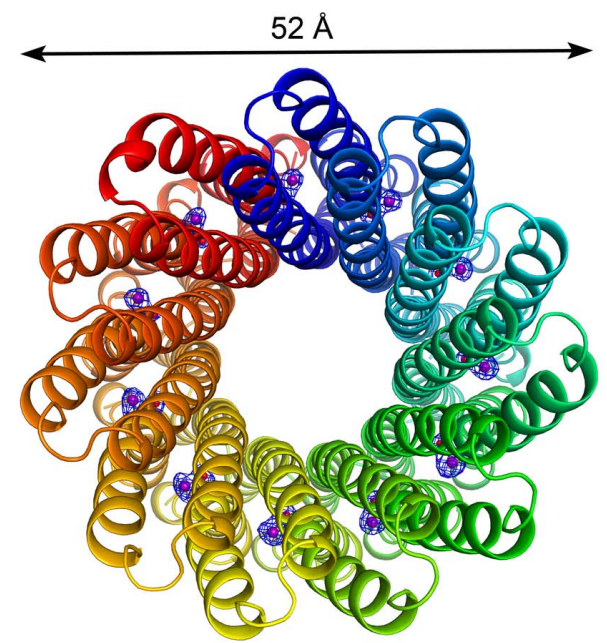

Figure 7. Crystal structure of the $c_{11}$ ring of the $F$. nucleatum ATP synthase at $2.2 \AA$ resolution. The pH of crystallization buffer was 5.3 , and included $100 \mathrm{mM} \mathrm{Na}^{+}$. (A) Side view of the c-ring along the membrane plane. The c-subunits are displayed in different colors in ribbon representation. The transmembrane region, $35 \AA$ in width, is indicated with grey bars. (B) View of the c-ring from the cytoplasm, along the perpendicular to the membrane. The sodium ion and the water molecule bound to each of the 11 ion-binding sites (purple and red spheres, respectively), are shown by $\mathrm{F}_{\mathrm{obs}} \mathrm{F}_{\text {calc }}$ omit electron-density maps at $3.2 \sigma$ (blue meshes).

doi:10.1371/journal.pbio.1001596.g007 

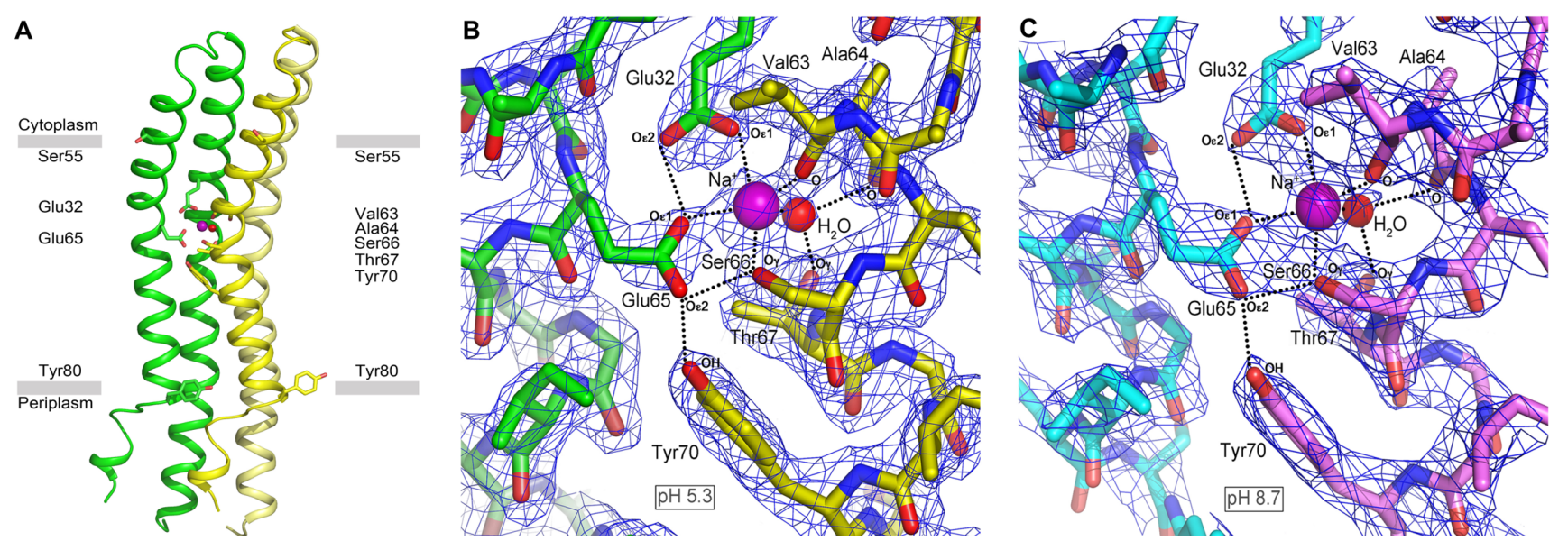

Figure 8. The $\mathrm{Na}^{+}$-binding site of the $F$. nucleatum $\mathrm{c}_{\mathbf{1 1}}$ ring at $\mathbf{p H} 5.3$ and 8.7. (A) A functional $\mathrm{Na}^{+}$-binding site consists of two adjacent $\mathrm{c}^{-}$ subunits (in yellow and green). Residues discussed in the text are indicated. (B) Close-up of the $\mathrm{Na}^{+}$-binding site viewed from the membrane plane, from a crystal grown at pH 5.3 and $100 \mathrm{mM} \mathrm{NaOAc}$; the resolution of the data is $2.2 \AA$. The $\mathrm{Na}^{+}$and a structural water molecule are shown in purple and red spheres, respectively. The $\mathrm{H}$-bond network and ion-protein interactions are indicated by dashed lines. Residues involved in $\mathrm{Na}^{+}$binding are labeled. (C) Close-up of the $\mathrm{Na}^{+}$binding site from a crystal grown at pH 8.7 and $100 \mathrm{mM}$ buffer, viewed as in (B); the resolution is $2.6 \AA$. Electron density maps ( $2 \mathrm{~F}_{\text {obs }}{ }^{-} \mathrm{F}_{\text {calc, }}$, blue mesh) are shown at $1.9 \sigma$. In both cases $\mathrm{Na}^{+}$ions can be discerned in the ion-binding sites, and consistently the key Glu65 side-chain is observed in the ion-locked conformation, while Glu32 is protonated.

doi:10.1371/journal.pbio.1001596.g008

ATP hydrolysis or ATP synthesis, even though they are concurrently bound to the c-ring binding sites, as the crystal structures and calculations demonstrate.

\section{Selectivity of c-ring Binding Sites with Two Carboxyl Side- Chains}

The structural basis for the ion specificity of the ATP synthase can be rationalized on the basis of the amino acid composition of the c-ring binding sites, and the concentrations of the two competing ions in the environment [8]. This study indicates that the $F$. nucleatum c-ring preferentially uses $\mathrm{Na}^{+}$as the coupling ion, but only under conditions in which $\mathrm{Na}^{+}$is in large excess over $\mathrm{H}^{+}$, e.g., in physiological settings. The c-ring is in fact selective for $\mathrm{H}^{+}$, like all other rings characterized thus far. In particular it appears to be $\sim 100$-fold more $\mathrm{H}^{+}$selective than the ring of the $\mathrm{Na}^{+-}$driven $\mathrm{V}$-type ATPase from $E$. hirae, which reportedly is almost nonselective [21]. The finding that the additional glutamate side-chain in the c-ring binding sites is constitutively protonated implies that its energetic contribution to ion selectivity is largely equivalent to that of a glutamine or asparagine side-chain at the same position. We expect this equivalence to hold true also for $\mathrm{H}^{+}$-driven ATP synthases with a double-carboxylate motif, such as those in Streptococcus pneumoniae [33] and M. tuberculosis (Figure S1). These crings probably bind two $\mathrm{H}^{+}$concurrently to each site (as in Figure 3A), only one of which is likely to be transported. This perspective would also be consistent with a recent study of the ATP synthase from the archaeon Methanosarcina acetivorans [19], whose c-ring binding sites were also predicted to feature two glutamate side-chains, one of which was proposed to be constitutively protonated. The $M$. acetivorans ATP synthase is reportedly coupled to both $\mathrm{Na}^{+}$and $\mathrm{H}^{+}$translocation under physiological conditions [19]. However, this is not due to the deprotonation of the atypical carboxyl side-chain in the c-ring (the equivalent to Glu32 in F. nucleatum), but rather to the increased $\mathrm{H}^{+}$ specificity of its binding sites, relative to $\mathrm{Na}^{+}$-driven c-ring rotors (Figure 3B). Physiologically, i.e., with $\mathrm{Na}^{+}$in large excess over $\mathrm{H}^{+}$, the more pronounced $\mathrm{H}^{+}$selectivity of the $M$. acetivorans c-ring makes the likelihood of a state with two bound $\mathrm{H}^{+}$comparable to that with one $\mathrm{Na}^{+}$and one $\mathrm{H}^{+}$, in contrast to $F$. nucleatum, for which the latter is the most probable.

The Undecameric Stoichiometry of $\mathrm{Na}^{+}$-Binding c-rings

Intriguingly, all $\mathrm{Na}^{+}$-coupled c-rings from F-type ATP synthases characterized so far consist of $11 \alpha$-helical hairpins, including those of I. tartaricus, P. modestum, A. woodii, C. paradoxum [24,34-36], and now $F$. nucleatum. The only apparent commonality of these bacteria is that they grow under anaerobic conditions and in environments where $\mathrm{Na}^{+}$is abundant (e.g., marine sediment). All

Table 1. Inter-atomic distances at the $\mathrm{Na}^{+}$binding sites of the F. nucleatum c-ring, in the crystals at $\mathrm{pH} 5.3$ and 8.7, and in simulation.

\begin{tabular}{|c|c|c|c|c|}
\hline From & To & $\begin{array}{l}\text { Distance }[\AA ̊] \\
\text { X-ray pH } 5.3^{\mathrm{a}}\end{array}$ & $\begin{array}{l}\text { Distance }[\AA] \\
\text { X-ray pH } 8.7^{a}\end{array}$ & $\begin{array}{l}\text { Distance [Å] } \\
\text { Simulation }^{\mathbf{b}}\end{array}$ \\
\hline $\mathrm{Na}^{+}$ & Glu32 O $\varepsilon 1$ & $2.35 \pm 0.07$ & $2.40 \pm 0.13$ & $2.33 \pm 0.14$ \\
\hline $\mathrm{Na}^{+}$ & Val63 O & $2.33 \pm 0.08$ & $2.36 \pm 0.09$ & $2.33 \pm 0.13$ \\
\hline $\mathrm{Na}^{+}$ & Glu65 Oع1 & $2.37 \pm 0.06$ & $2.43 \pm 0.07$ & $2.19 \pm 0.08$ \\
\hline $\mathrm{Na}^{+}$ & Ser66 O $\gamma$ & $2.32 \pm 0.07$ & $2.30 \pm 0.08$ & $2.32 \pm 0.09$ \\
\hline $\mathrm{Na}^{+}$ & $\mathrm{HOH}$ & $2.44 \pm 0.10$ & $2.46 \pm 0.09$ & $2.31 \pm 0.10$ \\
\hline $\mathrm{HOH}$ & Ala64 O & $2.61 \pm 0.12$ & $2.65 \pm 0.17$ & $2.72 \pm 0.12$ \\
\hline $\mathrm{HOH}$ & Thr67 O $\gamma$ & $2.69 \pm 0.15$ & $2.77 \pm 0.19$ & $2.82 \pm 0.13$ \\
\hline Glu65 Oع1 & Glu32 O 22 & $2.66 \pm 0.06$ & $2.67 \pm 0.09$ & $2.60 \pm 0.08$ \\
\hline Glu65 Oع2 & Tyr70 OH & $2.72 \pm 0.10$ & $2.81 \pm 0.10$ & $2.74 \pm 0.19$ \\
\hline Glu65 Oع2 & Ser66 O $\gamma$ & $2.52 \pm 0.09$ & $2.55 \pm 0.14$ & $2.73 \pm 0.18$ \\
\hline
\end{tabular}

${ }^{a}$ Crystallographic values are averages, with the corresponding standard deviations, over the 11 binding sites in each of the two c-rings found in the asymmetric unit. The structural refinement was carried out without noncrystallographic symmetry restraints on the $\mathrm{Na}^{+}$and $\mathrm{HOH}$ positions. ${ }^{b}$ The simulation values are time-averages extracted from the simulation of Model A (Figure 1A), over the 11 binding sites in the c-ring. The average structure of the c-ring backbone in simulation is superimposed on the crystal structure in Figure S14; the RMS difference is $0.74 \AA$.

doi:10.1371/journal.pbio.1001596.t001 


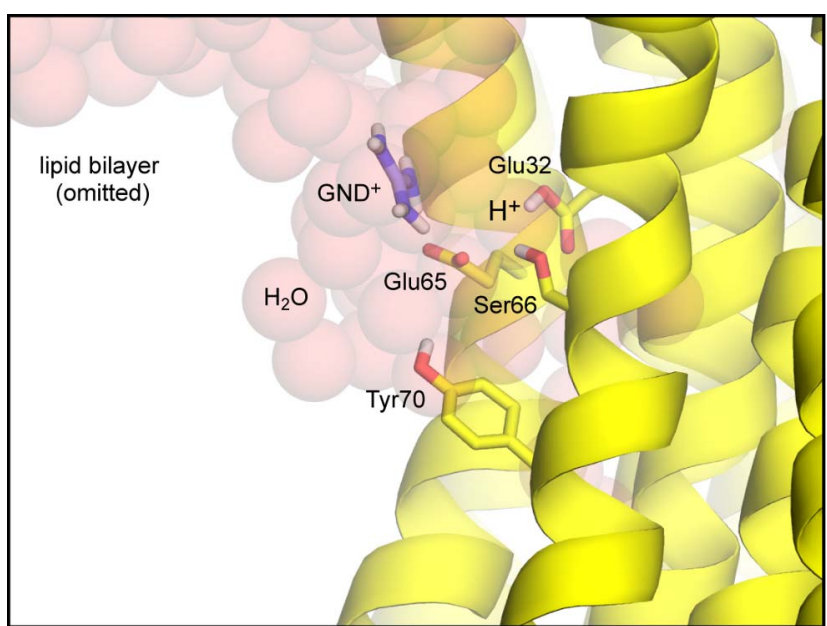

Figure 9. Simulation model of the open-state of the $\mathrm{Na}^{+}-$ binding site in the $F$. nucleatum c-ring. The c-ring is shown in cartoon format (yellow), viewed from the membrane plane. Lipid molecules in the surrounding membrane bilayer are omitted for clarity. A crevice of water molecules (transparent red spheres) was modeled on the cytoplasmic side of the protein-lipid interface, so as to mimic the hydrated environment at the interface of the c-ring and subunit $a$, in the complete enzyme. A guanidinium ion $\left(\mathrm{GND}^{+}\right)$was added to the crevice, to mimic a conserved Arg side-chain in the fourth transmembrane helix of subunit a. Key side-chains in the open binding site, namely Glu65, Glu32, Ser66, and Tyr70, are shown as sticks (non-polar hydrogen atoms are omitted); these form an interaction network in the closed state (Figure 8), which in this open state is largely disrupted. Glu65 projects out of the binding site and interacts with the guanidinium ion; Glu32, however, is highly likely to remain protonated (Figure 2B).

doi:10.1371/journal.pbio.1001596.g009

these organisms thus use the SMF to sustain ATP production, but a phylogenetic relationship among them is not apparent. A more evident similarity, besides the near-identical amino acid composition of the $\mathrm{Na}^{+}$-binding sites, is a glycine-rich motif in the $\mathrm{N}$ terminal helix of the c-subunit (Figure S1), which has been shown to have a strong influence on the stoichiometry of the c-ring $[14,37,38]$. It would be therefore tempting to hypothesize that the 11-hairpin architecture might reflect a universal feature of all
$\mathrm{Na}^{+}$-driven c-rings in F-type ATP synthases. Nevertheless, studies of A- and V-type rotary ATPases indicate that $\mathrm{Na}^{+}$specificity is compatible with other c-ring stoichiometries [20,39,40]. Consistently, single-point mutations of the glycine-motif in the $\mathrm{c}_{11}$ ring from $I$. tartaricus result in increased c-subunit stoichiometries, but do not necessarily impair $\mathrm{Na}^{+}$coupling [14]. Further experimental data will be required to clarify this question conclusively.

\section{ATP Synthase and c-rings of Human Pathogens as Potential Drug Targets}

In recent years, the ATP synthase has come into focus as a novel drug target [41]. Of particular interest is the finding that the $M$. tuberculosis c-ring can be inhibited by diarylquinolines, a new class of antibiotic compounds against multi-drug resistant strains $[42,43]$. Even in non-replicating or persister cells of $M$. tuberculosis, the PMF is obligatory for ATP homeostasis [44] and hence it is of medical interest to develop strategies to disrupt energy generation via the ATP synthase. This notion also holds true for F. nucleatum, which is a pervasive bacterium in dental plaque biofilms, and which is associated with periodontitis, one of the most common human infections [45]. The fact that the c-ring of the $F$. nucleatum ATP synthase is $\mathrm{Na}^{+}$-coupled and that its structure is significantly different from mitochondrial c-rings [13,28] opens an opportunity for new selective drugs against this opportunistic human pathogen.

\section{Materials and Methods}

\section{Molecular Modeling and Simulations}

Molecular dynamics (MD) simulations and free-energy calculations were based on a homology model of the $F$. nucleatum $\mathrm{c}_{11}$ ring embedded in a phospholipid membrane (Figure S2) as described previously [46]. The Free-Energy Perturbation (FEP) method was employed in all ion-selectivity and $\mathrm{pK}_{\mathrm{a}}$ calculations, as implemented in NAMD 2.7 [47]. Ab initio calculations were carried out with Gaussian09 (Frisch M.J. et al., Gaussian Inc., Wallingford CT, 2009) at the HF/6-31G* level. Further details see Text S1.

\section{F. nucleatum Culture Conditions}

F. nucleatum, subsp. nucleatum ATCC25586 was grown anaerobically at $37^{\circ} \mathrm{C}$ in Columbia broth (Difco) supplemented with cysteine-hydrochloride (reductant) and resazurin as an oxygen
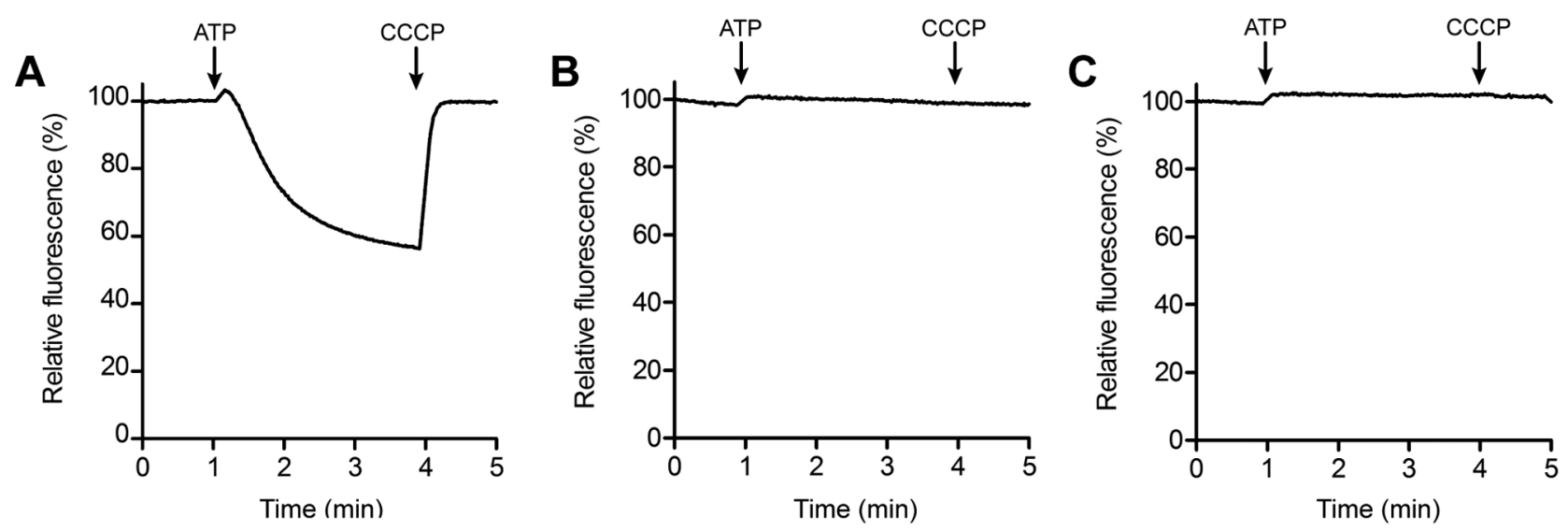

Figure 10. ATP-driven proton translocation in $E$. coli and $F$. nucleatum inverted membranes vesicles. Proton translocation was determined at $37^{\circ} \mathrm{C}$ by the quenching of acridine orange (AO) fluorescence. The reaction was initiated by the addition of $1.25 \mathrm{mM}$ ATP and terminated with $30 \mu \mathrm{M} \mathrm{CCCP}$ at the times indicated by arrows. (A) E. coli native membranes in $\mathrm{pH} 7.5$ buffer. (B) F. nucleatum native membranes in $\mathrm{pH} 6$ buffer with $1.25 \mathrm{mM} \mathrm{Na}{ }^{+}$-ATP; (C) Same as (B), with $10 \mathrm{mM} \mathrm{NaCl}$ added to the buffer.

doi:10.1371/journal.pbio.1001596.g010 
indicator ( $\mathrm{pH}$ 7.5). Cells were routinely grown in either anaerobic $\mathrm{N}_{2} / \mathrm{H}_{2} / \mathrm{CO}_{2}$ (90:5:5)-gassed Hungate tubes or in $1 \mathrm{l}$ Schott bottles. For further details see Text S1.

\section{Preparation of F. nucleatum Inverted Membrane Vesicles}

Cells grown to mid-exponential phase were passed three times through a French press cell $(20,000 \mathrm{psi})$ and the emulsion was centrifuged $(8,000 \mathrm{~g}$ for $10 \mathrm{~min})$ to remove cell debris. Inverted membrane vesicles were collected by ultracentrifugation, washed twice, and adjusted to a final protein concentration of $20-30 \mathrm{mg} /$ ml. For further details see Text Sl.

\section{Solubilization, Purification, and Biochemical Analysis of the $F$. nucleatum $\mathrm{F}_{1} \mathrm{~F}_{\mathrm{o}}$-ATP Synthase}

Inverted membrane vesicles were solubilized in reducing buffer $(\mathrm{pH} 7.5)$ using 2\% (w/v) dodecylmaltoside, 10\% (v/v) glycerol, and a protease inhibitor cocktail at $4{ }^{\circ} \mathrm{C}$ for $1 \mathrm{~h}$. The solubilizate was further purified by anion exchange chromatography and the ATP synthase-containing fractions were concentrated by ultrafiltration. The sample was further purified by gel filtration, desalted, and analyzed by SDS-PAGE. The identification of the $\mathrm{F}_{1} \mathrm{~F}_{\mathrm{o}}$-ATP synthase subunits was further confirmed by mass spectrometry (MALDI TOF/TOF MS). ATP hydrolysis activity was measured using the spectrophotometric ATP-regenerating assay or via the release of $\mathrm{P}_{\mathrm{i}}$. ATP-driven proton translocation was determined by the quenching of acridine orange $(\mathrm{AO})$, as described previously [48] with some modifications as described in Text S1. ATP synthesis in inverted membrane vesicles was determined via the standard luciferin-luciferase system, monitoring the light emitted with a chemiluminometer (FB 12 luminometer; Berthold) at $37^{\circ} \mathrm{C}$, as described before [49]. For further details see Text S1.

\section{Production, Purification, Biochemical Analysis, and Crystallization of the $F$. nucleatum c-ring}

The $F$. nucleatum $\mathrm{c}_{11}$ ring was produced in a heterologous hybrid ATP synthase expression system [50] forming the I. tartaricus ATP synthase $\left(\mathrm{F}_{1} \mathrm{ab}_{2}\right)$ and the $F$. nucleatum $\mathrm{c}_{11}$ ring. The purification of the c-ring was performed by a procedure as described in Text $\mathrm{S} 1$. NCD-4 labeling experiments were performed as previously [24] with slight modifications described in Text S1. Crystallization of the $F$. nucleatum $\mathrm{c}_{11}$ ring was performed by vapor diffusion in hanging drops at $18^{\circ} \mathrm{C}$. The crystals were flash-frozen in liquid nitrogen. For further details see Text S1.

\section{Data Collection, Structure Determination, and Data Deposition}

Data to $2.2 \AA(\mathrm{pH} \mathrm{5.3)}$ and $2.64 \AA(\mathrm{pH} 8.7)$ were collected at the Max-Planck/Novartis beamline X10SA (PXII) of the Swiss Light Source (SLS, Villigen, Switzerland) and the beamline ID23.2 of the European Synchrotron Radiation Facility (ESRF, Grenoble, France), respectively. Data processing and structure modeling was performed as described in Text S1. The atomic coordinates and structure factors of the $F$. nucleatum $\mathrm{c}_{11}$ ring at pH 5.3 and pH 8.7 were deposited in the Protein Data Bank, under the accession numbers $3 \mathrm{ZK} 1$, and $3 \mathrm{ZK} 2$, respectively.

\section{Supporting Information}

Figure S1 Alignment of c-subunit sequences from F-ATP synthases of selected species. The individual sequences were aligned according to their cytoplasmic loop region shown in bold. The single c-subunits form $\alpha$-helical hairpins, the $\mathrm{N}$ - and C-terminal $\alpha$-helices are highlighted in gray. The type of ion coordination $\mathrm{Na}^{+}$ or $\mathrm{H}^{+}$) is indicated on the right side, the question marks in color indicate the assumed type of coordinated ion. The residues involved in ion coordination $[6,39]$ are highlighted in colors and the glycine-

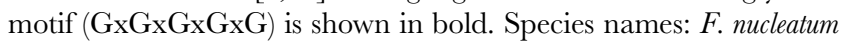
subsp. nucleatum (numbering), Ruminococcus albus, Thermotoga maritima, Eubacterium siraeum DSM 15702, Butyrivibrio proteoclasticus B316, Stomatobaculum longum, Oribacterium sp. oral taxon 078 str. F0262, Burkholderia pseudomallei, Azotobacter vinelandii, Gluconobacter oxydans, I. tartaricus, Propionigenium modestum, Clostridium paradoxum, Acetobacterium woodii, Mycoplasma genitalium, S. pneumoniae, M. tuberculosis, Aquifex aeolicus, Gloeobacter violaceus PCG 7421, Synechocystis sp. strain PCC 6803, Synoechococcus sp. strain PCG 6716, Arthrospira sp. strain PCC 9438, Spinacia oleracea (chloroplast), Bacillus sp. strain PS3, Caldalkalibacillus thermarum TA2.A1 (Bacillus sp. strain TA2.A1), Bacillus pseudofirmus OF4, Saccharomyces cerevisiae (mitochondria), Bos taurus (mitochondria), Haemophilus influenza, E. coli. The abbreviated phyla names are: Fu, Fusobacteria; Fi, Firmicutes; Th, Thermotogae; Pr, Proteobacteria; Ac, Actinobacteria; Aq Aquificae; Cy, Cyanobacteria; Vi, Viridiplantae, As, Ascomycota; Ch, Chordata.

(TIF)

Figure S2 Molecular model of the $F$. nucleatum c-ring embedded in a lipid membrane. (A) View along the membrane plane, with the cytoplasmic side of the protein (yellow) at the top. The lipid membrane consists of 237 1-palmitoyl-2oleoyl-sn-glycero-3-phosphocholine (POPG) molecules (blue), including those plugging the inner pore of the c-ring. The solvent includes $\sim 18,000$ water molecules (red) and 22 chloride ions (orange spheres), which counter the net charge of the protein and thus neutralize the system. (B) Cross-section of the model c-ring, highlighting the hairpin-like transmembrane topology of one of the c-subunits, as well as the location of the bound $\mathrm{Na}^{+}$ions (purple spheres) and the asymmetric lipid plug.

(TIF)

Figure S3 Alternative models of the ion-binding site in the $\boldsymbol{F}$. nucleatum c-ring, in the $\mathbf{H}^{+}$bound state. Hydrogen atoms in non-polar groups are omitted for clarity. In our models of the proton-bound state, $\mathrm{Na}^{+}$is replaced by $\mathrm{H}^{+}$, which binds to Glu65, while Glu32 remains also protonated. Note the hydrogenbond donated by Ser66 reorients accordingly. The water molecule that coordinates the bound $\mathrm{Na}^{+}$is either preserved - as in the model shown in Figure $3 \mathrm{~A}$ - or removed. (A) Alternate configuration of the site when a water molecule is preserved in the $\mathrm{H}^{+}$ bound state, similarly populated to that shown in Figure 3A. (B) Predicted structure of the site when the $\mathrm{H}^{+}$state does not include the water molecule included in the $\mathrm{Na}^{+}$state.

(TIF)

Figure S4 Effect of ionophores on the growth of $F$. nucleatum ATGG 25586 in batch culture. (A) CGCP was added to a final concentration (f.c.) of $50 \mu \mathrm{M}(\bigcirc), 100 \mu \mathrm{M}(\square)$ and $200 \mu \mathrm{M}(\Delta)$. (B) 2,4-dinitrophenol $(\mathrm{DNP})$ was added to a f.c. of $50 \mu \mathrm{M}(\bigcirc), 100 \mu \mathrm{M}(\square)$ and $200 \mu \mathrm{M}(\Delta)$. (C) 3,3', $4^{\prime}, 5-$ tetrachlorosalicylanilide (TCS) was added to a f.c. of $2 \mu \mathrm{M}$ (○), $5 \mu \mathrm{M}(\square)$, and $10 \mu \mathrm{M}(\Delta)$. (D) Monensin was added to a f.c. of $1 \mu \mathrm{M}(\bigcirc), 5 \mu \mathrm{M}(\square)$, and $10 \mu \mathrm{M}(\Delta)$. (E) Amiloride was added to a f.c. of $50 \mu \mathrm{M}(\bigcirc), 100 \mu \mathrm{M}(\square)$, and $200 \mu \mathrm{M}(\Delta)$. (F) 5 - $(\mathcal{N}$-ethyl- $\mathcal{N}$-isopropyl)amiloride (EIPA) was added to a f.c. of $50 \mu \mathrm{M}(\bigcirc), 100 \mu \mathrm{M}(\square)$, and $200 \mu \mathrm{M}(\Delta)$. Controls were grown with an equivalent volume of ethanol $(\bullet)$. The values plotted are the mean of three biological replicates and their standard errors.

(TIF) 
Figure S5 Effect of ATP synthase inhibitors on the growth of $\boldsymbol{F}$. nucleatum ATCG 25586 in batch culture. (A) DCCD was added to a final concentration of $100 \mu \mathrm{M}(\bigcirc)$, $200 \mu \mathrm{M}(\square)$, and $400 \mu \mathrm{M}(\Delta)$. (B) Tributyltin chloride (TBT-Cl) was added to a final concentration of $25 \mu \mathrm{M}(\bigcirc), 50 \mu \mathrm{M}(\square)$, and $150 \mu \mathrm{M}(\Delta)$. Controls were grown with an equivalent volume of ethanol $(\bullet$. The values plotted are the mean of three biological replicates and their standard errors.

(TIF)

Figure S6 ATP synthesis and ATP hydrolysis of $F$. nucleatum inverted membrane vesicles. (A) Effect of external $\mathrm{pH}$ on the ATPase activity catalyzed by an F-type ATP synthase. The activity was measured in $50 \mathrm{mM}$ MES-MOPS-Tris, $2 \mathrm{mM} \mathrm{MgCl} 2$ at $37^{\circ} \mathrm{C}$ by the ATP regenerating assay $(250 \mu \mathrm{g}$ membrane protein). $100 \%$ of ATPase activity corresponds to $0.09-0.15$ units $/ \mathrm{mg}$ protein $(\mathrm{mg} \quad \mathrm{P}) \quad(1$ unit $=1 \mu \mathrm{mol}$ ATP hydrolyzed/min). (B) ATP synthesis (in $\mathrm{nmol} / \mathrm{min} / \mathrm{mg}$ of protein) in inverted membrane vesicles was energized by a valinomycin $(2 \mu \mathrm{M})$-induced potassium diffusion potential $(100 \mathrm{mV})$ applied either in the absence (i) or in the presence (ii) of a chemical gradient of $\mathrm{Na}^{+}$. Effect of $5 \mu \mathrm{M}$ monensin (iii) or $150 \mu \mathrm{M}$ DCGD (iv) on ATP synthesis energized by a valinomycin-induced potassium diffusion potential, applied in presence of a chemical gradient of $\mathrm{Na}^{+}$. ATP synthesis with no added valinomycin in the absence (v) or in the presence (vi) of a chemical gradient of $\mathrm{Na}^{+}$. All inhibitors were preincubated with the inverted membrane vesicles for $10 \mathrm{~min}$ prior to the addition of valinomycin.

(TIF)

Figure S7 Analysis of purified $F$. nucleatum ATP synthase by silver-stained $\mathbf{1 2 . 5 \%}$ SDS-PAGE. Lane 1 , prestained molecular mass marker (ThermoScientific), indicated in $\mathrm{kDa}$; lane 2 , selected fraction $(2.3 \mu \mathrm{g}$ protein) from gel filtration column. The identity and molecular mass of the constituent protein subunits in $\mathrm{kDa}$ are indicated on the right. MALDI mass spectrometry analysis identified subunits $\alpha, \beta, \gamma, \delta$, and $\mathrm{b}$ (unpublished data). The bands for the $c_{11}$ ring and the $\beta$-subunit overlap.

(TIF)

Figure S8 Catalytic activity of the purified $F_{1} F_{o}$-ATP synthase from $\boldsymbol{F}$. nucleatum. (A) Hydrolytic activity of the ATP synthase in membranes, soluble fraction (DDM extracted) and purified protein over time (all stored at $4^{\circ} \mathrm{C}$ ). (B) Effect of ATP on hydrolytic activity of the purified enzyme at $37^{\circ} \mathrm{C}$. (C) Effect of $\mathrm{MgCl}_{2}$ on hydrolytic activity at $37^{\circ} \mathrm{C}$. The ATPase activity was determined using the ATP regenerating assay $(120-140 \mu \mathrm{g}$ protein) in (A), (B), and the $\mathrm{P}_{\mathrm{i}}$ assay $(60-70 \mu \mathrm{g}$ protein) in $(\mathrm{C})$. $100 \%$ of activity corresponds to 0.15 units $/ \mathrm{mg}$ of protein for membrane vesicles and $1-2$ units $/ \mathrm{mg}$ for the purified protein at $\mathrm{pH}$ 7.5. The ATP hydrolysis assay mixture contained $50 \mathrm{mM}$ MOPS, $2 \mathrm{mM} \mathrm{MgCl}_{2}$ (pH 7.5). The values plotted are representative of two to three biological replicates; the statistical variance was less than $20 \%$.

(TIF)

Figure S9 Inhibition of the purified $F$. nucleatum ATP synthase by DCCD. The purified protein $(120-140 \mu \mathrm{g})$ was incubated at $25^{\circ} \mathrm{C}$ in $50 \mathrm{mM}$ MOPS, $2 \mathrm{mM} \mathrm{MgCl}_{2}$, pH 7.5 for 20 min, with the DCCD concentrations indicated. The control sample was incubated with an equal amount of ethanol. The ATPase activity was quantified using the ATP-regenerating assay. $100 \%$ of activity corresponds to $1-2 \mu \mathrm{mol} \mathrm{ATP} / \mathrm{min} / \mathrm{mg}$ of protein. Values are representative of two to three separate experiments; the statistical variance was less than $20 \%$.

(TIF)
Figure S10 Silver-stained SDS-PAGE of the purified $c_{11}$ ring from $\boldsymbol{F}$. nucleatum. Lane $1,1 \mu \mathrm{g}$ of $\mathrm{c}_{11}$ ring; lane $2,1 \mu \mathrm{g}$ of c-ring precipitated with $15 \%(\mathrm{w} / \mathrm{v})$ trichloroacetic acid. The cmonomer $\left(\mathrm{c}_{1}\right)$, c-dimer $\left(\mathrm{c}_{2}\right)$, and c-oligomer $\left(\mathrm{c}_{11}\right)$ are indicated on the right. A molecular weight marker (M, PageRuler Unstained Protein Ladder, Fermentas) in $\mathrm{kDa}$ is given on the left.

(TIF)

Figure S11 Determination of the c-subunit mass from the isolated c-ring of $\boldsymbol{F}$. nucleatum by MALDI-MS. The theoretical mass of the c-monomer is 8,862.94 Da (unformylated) and 8,890.94 $\mathrm{Da}$ (formylated); the theoretical mass of the formylated, single-oxidized c-monomer is 8,906.94 Da, and 8,922.94 Da for the double-oxidized form.

(TIF)

Figure S12 Long-term kinetics of NCD-4 modification of detergent-solubilized c-rings from $F$. nucleatum, without the addition of $\mathbf{N a}^{+}$. A $27 \mu \mathrm{g}$ c-ring sample in $0.5 \mathrm{M}$ MES buffer pH 5.7 containing $1.5 \%$ (w/v) n-octyl- $\beta$-D-glycoside was monitored in a fluorescence spectrophotometer $\left(\lambda_{\mathrm{ex}}=342 \mathrm{~nm}\right.$, $\lambda_{\mathrm{em}}=452 \mathrm{~nm}$ ) at selected time points for a total of $120 \mathrm{~min}$. The reaction was initiated by the addition of $100 \mu \mathrm{M}$ NCD-4 (in $10 \%$ $(\mathrm{w} / \mathrm{v}) \beta$-dodecyl-maltoside) at time point 0 . The arrow indicates the time point at which the NCD-4 labeling of the c-ring was stopped in the experiment reported in Figure 6, by addition of $15 \mathrm{mM} \mathrm{NaCl}$. (TIF)

Figure S13 SDS-PAGE of the c-ring and the c-monomer from $F$. nucleatum after reaction with NCD-4. The NCD-4 modified $F$. nucleatum $\mathrm{c}_{11}$ ring was loaded on a $13.2 \%$ SDS-polyacrylamide gel. The same sample was also precipitated using $15 \%(\mathrm{w} / \mathrm{v})$ trichloroacetic acid (+TCA), resulting in monomeric c-subunits (as indicated). (A) Silverstained SDS-polyacrylamide gel, showing a shift in the apparent molecular mass of $c_{11}$ rings, $c_{1}$ monomers, and $c_{2}$ dimers, after binding of NCD-4 (thin dashed lines). Unmodified (non NCD-4 treated) samples were added for comparison, showing a slightly faster migration. (B) UV-light exposed SDSpolyacrylamide gel, showing the fluorescence of the NCD-4 modified $c_{11}$ rings and $c_{1}$ monomers. Two molecular mass markers (M1, PageRuler Unstained Protein Ladder, Fermentas and M2, PageRuler Prestained Protein Ladder, Fermentas) are indicated in $\mathrm{kDa}$ on the left side of both gels.

(TIF)

Figure S14 Comparison of the experimental and predicted structures of the $\boldsymbol{F}$. nucleatum c-ring. The experimental structure (blue cartoons) is that obtained by $\mathrm{X}$-ray crystallography at $\mathrm{pH}$ 5.3. The predicted structure (red cartoons) is a time-average calculated from the simulation of model A (Figure 1A), which was generated by homology with the c-ring of $I$. tartaricus. The RMS difference between the backbone conformations is $0.74 \AA$. The c-ring is viewed (A) from the plane of the membrane, and (B) along the membrane perpendicular. (TIF)

Table S1 Purification of the $F$. nucleatum $F_{1} F_{0}-A T P$ synthase.

(DOC)

Table S2 Collection of X-ray diffracion data and refinement statistics.

(DOG)

Text S1 Supporting materials and methods, and references.

(DOC) 


\section{Acknowledgments}

We thank Julian Langer for his assistance with the MALDI-MS measurements of the $F$. nucleatum c-subunit. We also thank the staff of the Swiss Light Source (SLS, PXII) and the European Synchrotron Radiation Facility (ESRF, ID23-2) for their assistance at the beamlines, and the Jülich Supercomputer Center for computational resources. TM acknowledges Werner Kühlbrandt for his generous support of TM's laboratory.

\section{References}

1. Abrahams JP, Leslie AGW, Lutter R, Walker JE (1994) Structure at $2.8 \AA$ resolution of $\mathrm{F}_{1}$-ATPase from bovine heart-mitochondria. Nature 370: 621-628.

2. Boyer PD (1993) The binding change mechanism for ATP synthase - some probabilities and possibilities. Biochim Biophys Acta 1140: 215-250.

3. Yoshida M, Muneyuki E, Hisabori T (2001) ATP synthase: a marvellous rotary engine of the cell. Nat Rev Mol Cell Biol 2: 669-677.

4. Junge W, Sielaff H, Engelbrecht S (2009) Torque generation and elastic power transmission in the rotary $\mathrm{F}_{\mathrm{o}} \mathrm{F}_{1}$-ATPase. Nature 459: 364-370.

5. Meier T, Faraldo-Gómez J, Börsch M (2011) ATP synthase: a paradigmatic molecular machine. Frank J, editor. Molecular machines in biology. Cambridge: Cambridge University Press pp. 208-238.

6. Meier T, Polzer P, Diederichs K, Welte W, Dimroth P (2005) Structure of the rotor ring of F-type $\mathrm{Na}^{+}$-ATPase from Ilyobacter tartaricus. Science 308: 659-662.

7. Pogoryelov D, Yidiz Ö, Faraldo-Gómez JD, Meier T (2009) High-resolution structure of the rotor ring of a proton-dependent ATP synthase. Nat Struct Mol Biol 16: 1068-1073.

8. Krah A, Pogoryelov D, Langer JD, Bond PJ, Meier T, et al. (2010) Structural and energetic basis for $\mathrm{H}^{+}$versus $\mathrm{Na}^{+}$binding selectivity in ATP synthase $\mathrm{F}_{\mathrm{o}}$ rotors. Biochim Biophys Acta 1797: 763-772.

9. Meier T, Krah A, Bond PJ, Pogoryelov D, Diederichs K, et al. (2009) Complete ion-coordination structure in the rotor ring of $\mathrm{Na}^{+}$-dependent F-ATP synthases. J Mol Biol 391: 498-507.

10. Preiss L, Yildiz Ö, Hicks DB, Krulwich TA, Meier T (2010) A new type of proton coordination in an $\mathrm{F}_{1} \mathrm{~F}_{\mathrm{o}}$-ATP synthase rotor ring. PLoS Biol 8: e1000443.

11. Leone V, Krah A, Faraldo-Gómez JD (2010) On the question of hydronium binding to ATP-synthase membrane rotors. Biophys J 99: L53-55.

12. Ferguson SJ (2010) ATP synthase: from sequence to ring size to the $\mathrm{P} / \mathrm{O}$ ratio. Proc Natl Acad Sci U S A 107: 16755-16756.

13. Watt IN, Montgomery MG, Runswick MJ, Leslie AGW, Walker JE (2010) Bioenergetic cost of making an adenosine triphosphate molecule in animal mitochondria. Proc Natl Acad Sci U S A 107: 16823-16827.

14. Pogoryelov D, Klyszejko AL, Krasnoselska GO, Heller EM, Leone V, et al. (2012) Engineering rotor ring stoichiometries in the ATP synthase. Proc Natl Acad Sci U S A 109: E1599-E1608.

15. Bakken V, Hogh BT, Jensen HB (1989) Utilization of amino-acids and peptides by Fusobacterium nucleatum. Scand J Dent Res 97: 42-53.

16. Beatrix B, Bendrat K, Rospert S, Buckel W (1990) The biotin-dependent sodium-ion pump glutaconyl-CoA decarboxylase from Fusobacterium nucleatum (subsp. nucleatum): comparison with the glutaconyl-CoA decarboxylases from gram-positive bacteria. Arch Microbiol 154: 362-369.

17. Kapatral V, Anderson I, Ivanova N, Reznik G, Los T, et al. (2002) Genome sequence and analysis of the oral bacterium Fusobacterium nucleatum strain ATCC 25586. J Bacteriol 184: 2005-2018.

18. Jones PC (2001) Introduction of a carboxyl group in the first transmembrane helix of Escherichia coli $\mathrm{F}_{1} \mathrm{~F}_{\mathrm{o}}$ ATPase subunit $\mathrm{c}$ and cytoplasmic $\mathrm{pH}$ regulation. J Bacteriol 183: 1524-1530.

19. Schlegel K, Leone V, Faraldo-Gómez JD, Müller V (2012) Promiscuous archaeal ATP synthase concurrently coupled to $\mathrm{Na}^{+}$and $\mathrm{H}^{+}$translocation. Proc Natl Acad Sci U S A 109: 947-952.

20. Mayer F, Leone V, Langer JD, Faraldo-Gómez JD, Müller V (2012) A c subunit with four transmembrane helices and one ion $\left(\mathrm{Na}^{+}\right)$binding site in an archaeal ATP synthase: implications for c ring function and structure. J Biol Chem 287: 327-337.

21. Murata T, Yamato I, Kakinuma Y, Shirouzu M, Walker JE, et al. (2008) Ion binding and selectivity of the rotor ring of the $\mathrm{Na}^{+}$-transporting V-ATPase. Proc Natl Acad Sci U S A 105: 8607-8612.

22. Laubinger W, Dimroth $\mathrm{P}(1987)$ Characterization of the $\mathrm{Na}^{+}$-stimulated ATPase of Propionigenium modestum as an enzyme of the $\mathrm{F}_{1} \mathrm{~F}_{\mathrm{o}}$ type. Eur J Biochem 168: 475-480.

23. Laubinger W, Dimroth P (1988) Characterization of the ATP synthase of Propionigenium modestum as a primary sodium pump. Biochemistry 27: 7531-7537.

24. Meier T, Matthey U, von Ballmoos C, Vonck J, von Nidda TK, et al. (2003) Evidence for structural integrity in the undecameric c-rings isolated from sodium ATP synthases. J Mol Biol 325: 389-397.

25. Pogoryelov D, Krah A, Langer JD, Yildiz Ö, Faraldo-Gómez JD, et al. (2010) Microscopic rotary mechanism of ion translocation in the $\mathrm{F}_{\mathrm{o}}$ complex of ATP synthases. Nat Chem Biol 6: 891-899.

26. Steed PR, Fillingame RH (2008) Subunit a facilitates aqueous access to a membrane-embedded region of subunit $\mathrm{c}$ in Escherichia coli $\mathrm{F}_{1} \mathrm{~F}_{\mathrm{o}}$ ATP synthase. J Biol Chem 283: 12365-12372.

\section{Author Contributions}

The author(s) have made the following declarations about their contributions: Conceived and designed the experiments: GMC JDFG TM. Performed the experiments: SS MIC AK VL DM. Analyzed the data: SS MIC AK ÖY VL DM GMC JDFG TM. Contributed reagents/ materials/analysis tools: Ö. Wrote the paper: GMC JDFG TM.

27. Steed PR, Fillingame RH (2009) Aqueous accessibility to the transmembrane regions of subunit c of the Escherichia coli $\mathrm{F}_{1} \mathrm{~F}_{\mathrm{o}}$ ATP synthase. J Biol Chem 284: 23243-23250.

28. Symersky J, Pagadala V, Osowski D, Krah A, Meier T, et al. (2012) Structure of the $\mathrm{c}_{10}$ ring of the yeast mitochondrial ATP synthase in the open conformation. Nat Struct Mol Biol 19: 485-491.

29. Mizutani K, Yamamoto M, Suzuki K, Yamato I, Kakinuma Y, et al. (2011) Structure of the rotor ring modified with $\mathcal{N}_{\mathcal{N}^{\prime}}$-dicyclohexylcarbodiimide of the $\mathrm{Na}^{+}$-transporting vacuolar ATPase. Proc Natl Acad Sci U S A 108: 13474 13479.

30. Vik SB, Antonio BJ (1994) A mechanism of proton translocation by $\mathrm{F}_{1} \mathrm{~F}_{\mathrm{o}}$ ATP synthases suggested by double mutants of the a subunit. J Biol Chem 269: 30364-30369.

31. Junge W, Lill H, Engelbrecht S (1997) ATP synthase: an electrochemical transducer with rotary mechanics. TIBS 22: 420-423.

32. Zhang $\mathrm{Y}$, Fillingame RH (1994) Essential aspartate in subunit $\mathrm{c}$ of $\mathrm{F}_{1} \mathrm{~F}_{\mathrm{o}}$ ATP synthase. Effect of position 61 substitutions in helix-2 on function of Asp24 in helix-1. J Biol Chem 269: 5473-5479.

33. Ferrándiz MJ, de la Campa AG (2002) The membrane-associated $\mathrm{F}_{\mathrm{o}} \mathrm{F}_{1}$ ATPase is essential for the viability of Streptococcus pneumoniae. FEMS Microbiol Lett 212: 133-138.

34. Stahlberg H, Müller DJ, Suda K, Fotiadis D, Engel A, et al. (2001) Bacterial $\mathrm{Na}^{+}$-ATP synthase has an undecameric rotor. EMBO Rep 2: 229-233.

35. Meier T, Ferguson SA, Cook GM, Dimroth P, Vonck J (2006) Structural investigations of the membrane-embedded rotor ring of the F-ATPase from Clostridium paradoxum. J Bacteriol 188: 7759-7764.

36. Fritz M, Klyszejko AL, Morgner N, Vonck J, Brutschy B, et al. (2008) An intermediate step in the evolution of ATPases: a hybrid $\mathrm{F}_{0}-\mathrm{V}_{0}$ rotor in a bacterial $\mathrm{Na}^{+} \mathrm{F}_{1} \mathrm{~F}_{\mathrm{o}}$ ATP synthase. FEBS Journal 275: 1999-2007.

37. Liu J, Fackelmayer OJ, Hicks DB, Preiss L, Meier T, et al. (2011) Mutations in a helix-1 motif of the ATP synthase c-subunit of Bacillus pseudofirmus OF4 cause functional deficits and changes in the c-ring stability and mobility on sodium dodecyl sulfate-polvacrylamide gel electrophoresis. Biochemistry 50: 5497-5506.

38. Preiss L, Klyszejko AL, Hicks DB, Liu J, Fackelmayer OJ, et al. (2013) The cring stoichiometry of ATP synthase is adapted to cell physiological requirements of alkaliphilic Bacillus pseudofirmus OF4. Proc Natl Acad Sci U S A 110:78747879

39. Murata T, Yamato I, Kakinuma Y, Leslie AGW, Walker JE (2005) Structure of the rotor of the V-type $\mathrm{Na}^{+}$-ATPase from Enterococcus hirae. Science 308: 654 659.

40. Vonck J, Pisa KY, Morgner N, Brutschy B, Müller V (2009) Three-dimensional structure of $\mathrm{A}_{1} \mathrm{~A}_{\mathrm{o}}$ ATP synthase from the hyperthermophilic archaeon Pyrococcus furiosus by electron microscopy. J Biol Chem 284: 10110-10119.

41. Balemans W, Vranckx L, Lounis N, Pop O, Guillemont J, et al. (2012) Novel antibiotics targeting respiratory ATP synthesis in gram-positive pathogenic bacteria. Antimicrob Agents Ch 56: 4131-4139.

42. Andries K, Verhasselt P, Guillemont J, Gohlmann HW, Neefs JM, et al. (2005) A diarylquinoline drug active on the ATP synthase of Mycobacterium tuberculosis. Science 307: 223-227.

43. Bald D, Koul A (2010) Respiratory ATP synthesis: the new generation of mycobacterial drug targets? FEMS Microbiol Lett 308: 1-7.

44. Rao SP, Alonso S, Rand L, Dick T, Pethe K (2008) The protonmotive force is required for maintaining ATP homeostasis and viability of hypoxic, nonreplicating Mycobacterium tuberculosis. Proc Natl Acad Sci U S A 105: 11945-11950.

45. Signat B, Roques C, Poulet P, Duffaut D (2011) Role of Fusobacterium nucleatum in periodontal health and disease. Curr Issues Mol Biol 13: 25-35.

46. Staritzbichler R, Anselmi C, Forrest LR, Faraldo-Gómez JD (2011) GRIFFIN: A versatile methodology for optimization of protein-lipid interfaces for membrane protein simulations. J Chem Theor Comp 7: 1167-1176.

47. Phillips JC, Braun R, Wang W, Gumbart J, Tajkhorshid E, et al. (2005) Scalable molecular dynamics with NAMD. J Comput Chem 26: 1781-1802.

48. Keis S, Stocker A, Dimroth P, Cook GM (2006) Inhibition of ATP hydrolysis by thermoalkaliphilic $\mathrm{F}_{1} \mathrm{~F}_{\mathrm{o}}$-ATP synthase is controlled by the $\mathrm{C}$-terminus of the $\varepsilon$ subunit. J Bacteriol 188: 3796-3804.

49. Ferguson SA, Keis S, Cook GM (2006) Biochemical and molecular characterization of a $\mathrm{Na}^{+}$-translocating $\mathrm{F}_{1} \mathrm{~F}_{0}$-ATPase from the thermoalkaliphilic bacterium Clostridium paradoxum. J Bacteriol 188: 5045-5054.

50. Vorburger T, Ebneter JZ, Wiedenmann A, Morger D, Weber G, et al. (2008) Arginine-induced conformational change in the c-ring/a-subunit interface of ATP synthase. FEBS J 275: 2137-2150. 